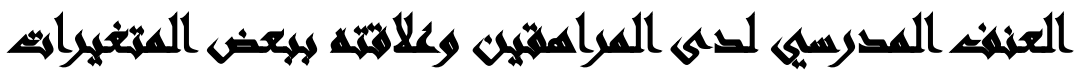

\section{المئئية}

\section{$[1 \cdot]$}

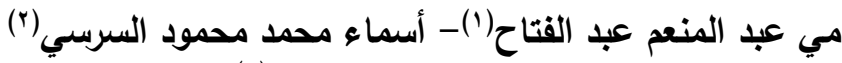

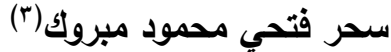

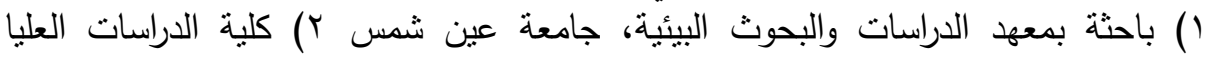
للطفولة، جامعة عين شمس ب) المعهد العالي للخدمة الاجتماعية ببنها، جامعة بنها

\section{(المستخلصى}

هدف الدراسة الحالية إلى التعرف على بعض المتغيرات البيئية والفيزيقية وعلاقتها

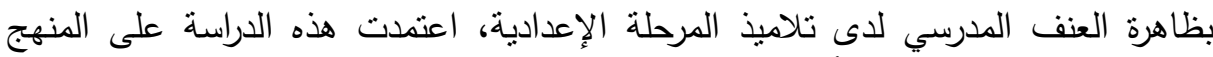

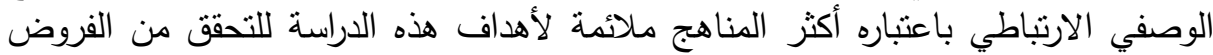

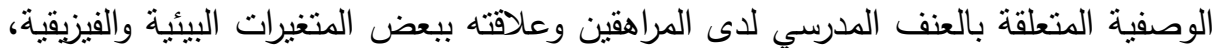

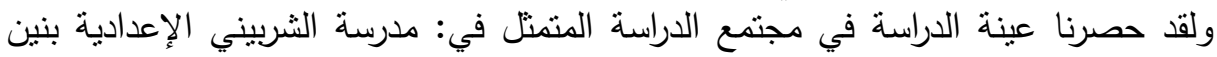

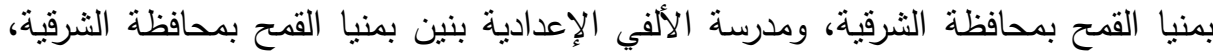

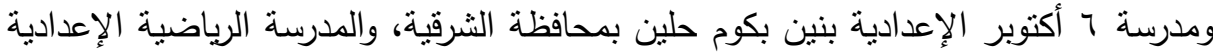

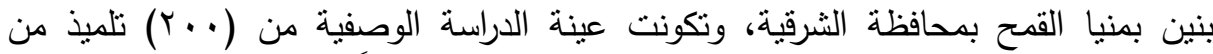

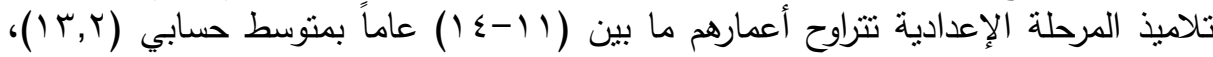

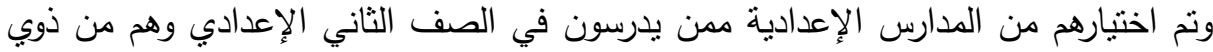

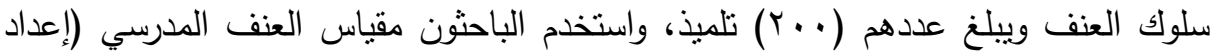

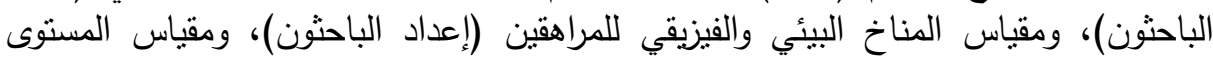

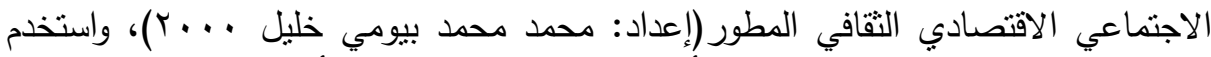

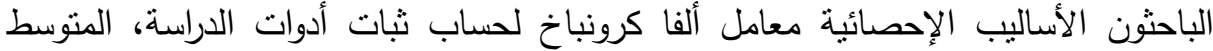

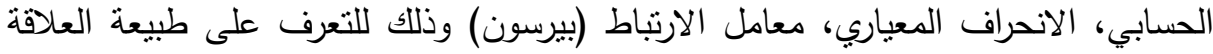

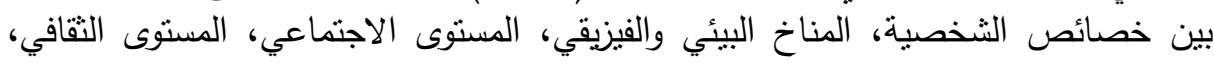

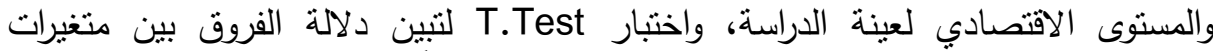

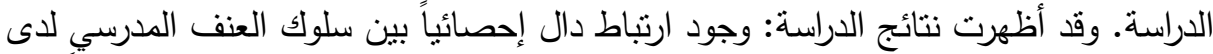

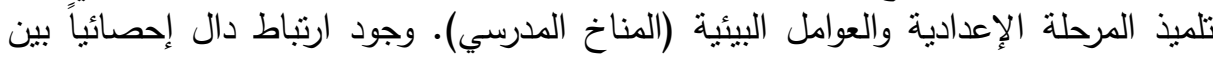
سلوك العنف المدرسي لاى تلاميذ المرحلة الإعدادية والعوامل الفيزيقية (المناخ الأسربي).

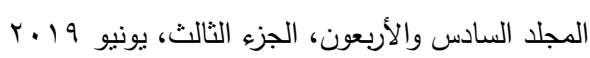


وجود ارتباط دال إحصائياً بين سلوك العنف المدرسي لدى تلاميذ المرحلة الإعدادية والمسنوى الإئي

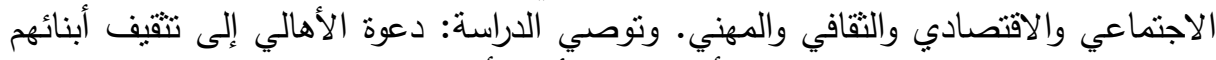

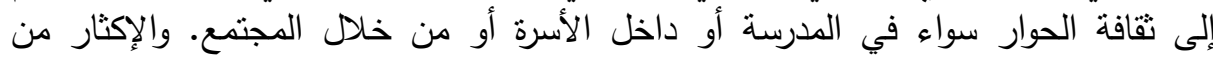

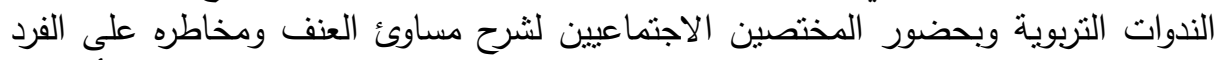

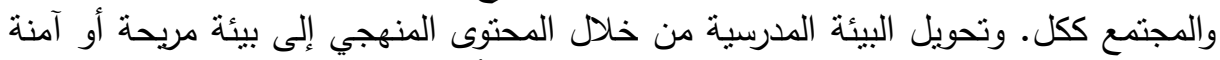
تتجعها على العطاء والإبداع وروح التعاون والمحبة بين أفرادها وحب العلم. العنا.

\section{Xaxid}

يعد العنف مشكلة متعددة الأبعاد فهي تتضمن أبعاداً تربوية ونفسية واجتماعية واقتصادية ولقد لفتت أنظار علماء النفس والمهتمين بالتربية والتعليم وعلماء الاجتماع فدرسوا أبعادها وأسبابها والعوامل المؤدية إليها، وفي الآونة الأخيرة تفتت ظاهرة العنف في مجتمعاتتا العربية

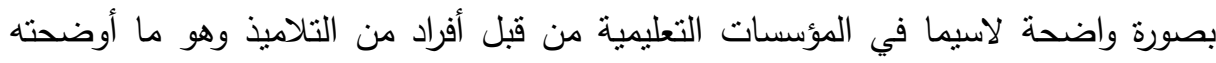

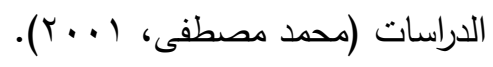

تعد ظاهرة العنف الددرسي من بين المشاكل العويصة التي أصبحت تعانيها منظومتتا التربوية، الأمر الذي لطالما أسفر عن ارتكاب مجموعة من الجرائم في حق تلاميذ، وأساتذة

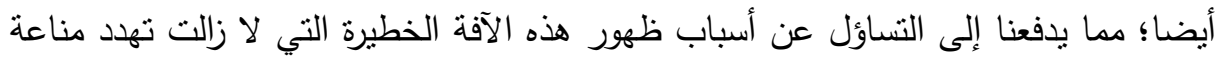

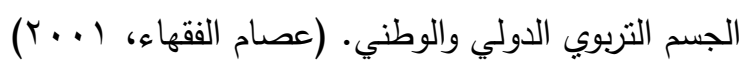

إن الاهتمام والالتفات إلى ظاهرة العنف كان نتيجة نطور وعي عام في مطلع القرن

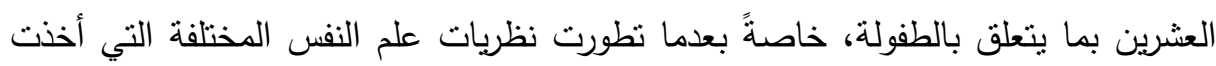
تفسر لنا سلوكيات الإنسان على ضوء مرحلة الطفولة المبكرة وأهميتها بتكوين ذات الفورئ الفرد وتأثيرها على حياته فيما بعد، وضرورة نوفير الأجواء الحيانية المناسبة لينمو الأطفال نمواً

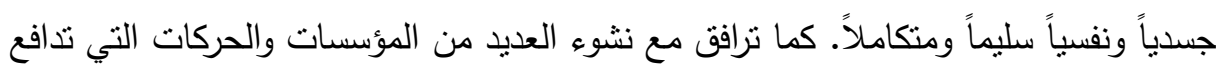

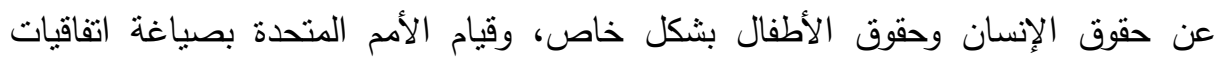

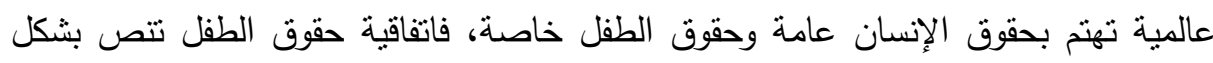

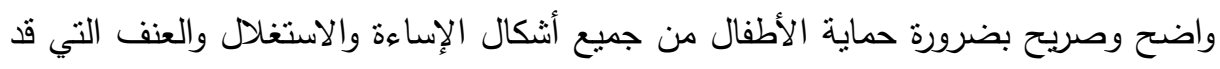
يتعرضون لها (المادة r ب، اتفاقية حقوق الطفل) وهذا يشير إلى بداية الاهتمام بالطفل على الإنى 
أنه إنسان له كيان وحقوق بحد ذاته وليس تابع أو ملكية لأحد مثل العائلة (عامر بن شايع،

ومن وجهة نظر الباحثون تتضح المشكلة الرئيسية لهذه الدراسة بشقيها النظري والميداني

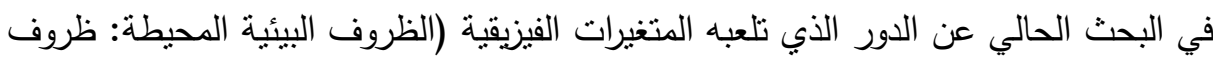
مناخية، وظروف معيشية ومكانية)، والمتغيرات البيئية (التنشئة الاجتماعية، المعاملة الوالدية، لكئه

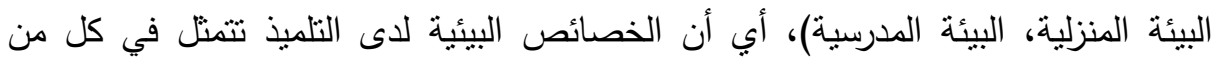

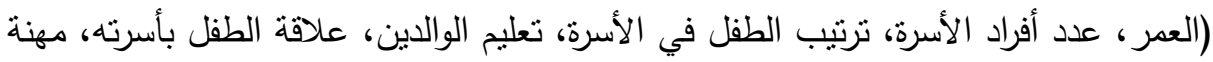

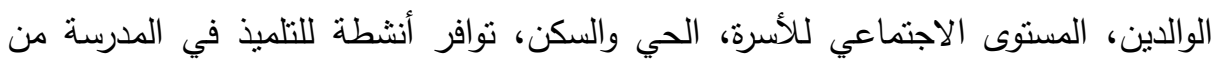

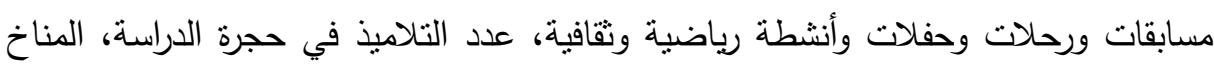
المدرسي، خصائص حجرة الدراسة، معاملة المعلمين، ... الخ).

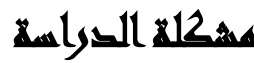

تسجل ظواهر العنف المدرسي بحدة في مؤسساتتا التربوية إذا تبقى الظروف الاجتماعية

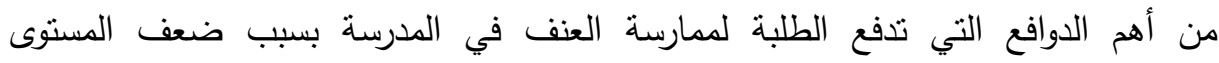
الاجتماعي والمهني للأسرة وظروف الحرمان الاجتماعي والقهر النفسي والإحباط، كل هذه

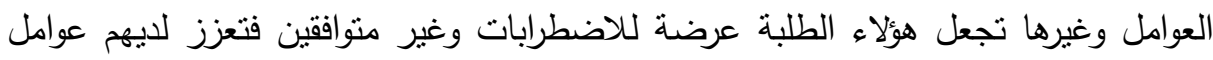

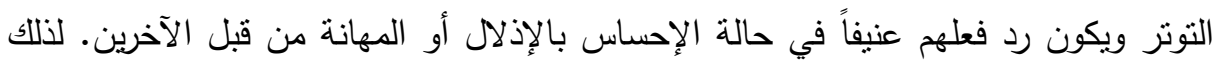

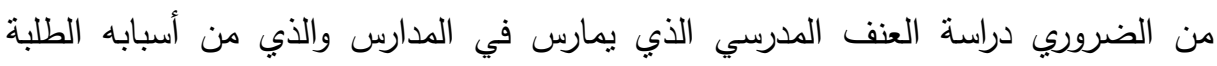

$$
\text { والمدرسون والأسرة (عصام الفقهاء، ( ... بـ). }
$$

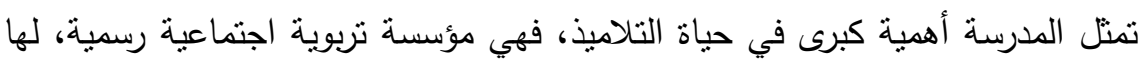

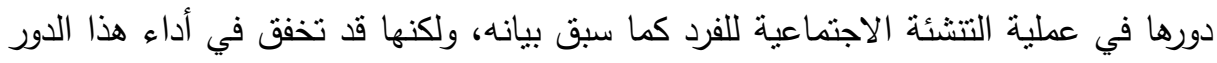
لأسباب متعددة، وقد عانى الكثير من المجتمعات من ظاهرة العنف المدرسي، ففي الولايات

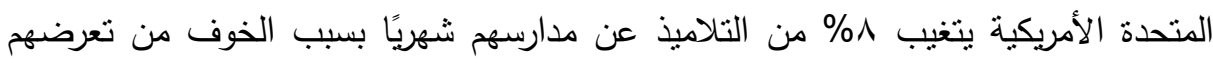
للعنف من قبل التلاميذ الآخرين، كما يتعرض للعنف أكثر من ربع مليون تلميذ شهريًا، ويواجه

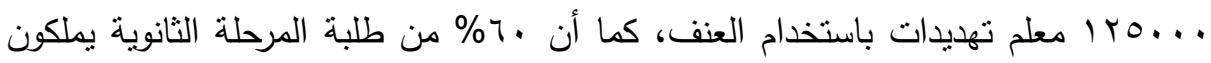

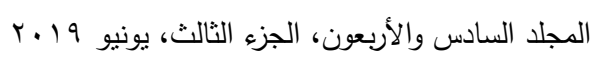


أسلحة، وفي مصر ونظراً لوجود عوامل - وسوف نذكرها بالتفصيل لاحقاً - انتشار العنف في المدارس، وجود أنماط متعددة للعنف في المدارس، ويتضح ارتباط المدرسة بالعنف من خلال

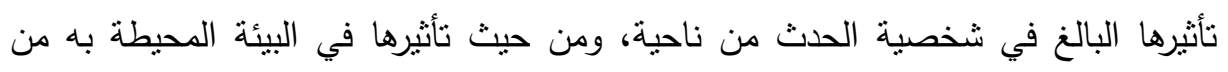

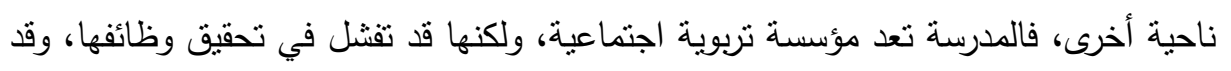

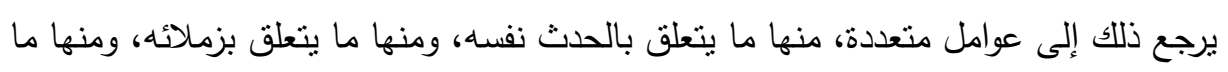

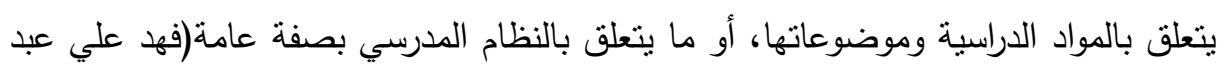

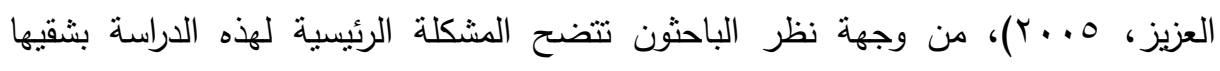

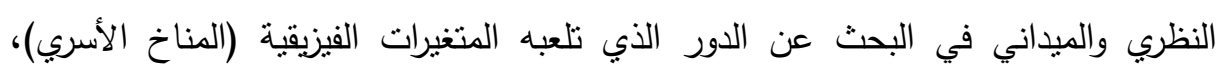

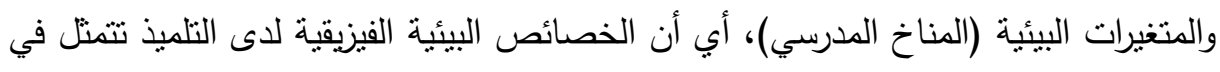
كل من (العمر، عدد أفراد الأسرة، ترتيب الطفل في الأسرة، تعليم الوالدين، علاقة الطئية الطفل

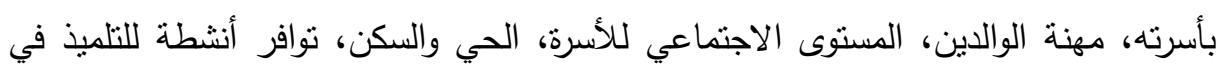

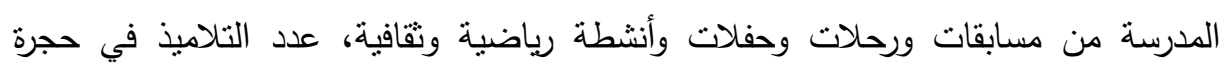

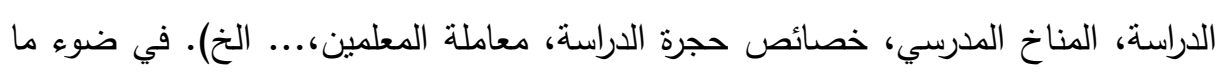
سبق يمكن تحديد أسئلة البحث في الأسئلة الآتية:

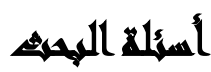

1-ما مدى وجود علاقة بين سلوك العنف المدرسي لدى تلاميذ المرحلة الإعدادية والعوامل

البيئية؟

ץ-ما مدى وجود علاقة بين سلوك العنف المدرسي لاى تلاميذ المرحلة الإعدادية والعوامل

الفيزيقية؟ 


\section{أهمية الصوراسما}

الأهمية النظرية:

ا-تتبع أهمية هذه الدراسة من خلال بحثها لظاهرة سلوكية تزداد معدلاتها في الآونة الأخيرة

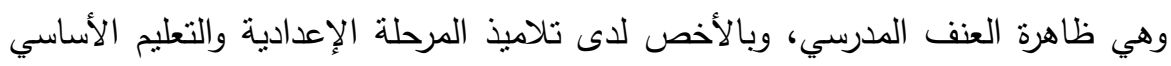

تمثل بداية حقيقية لمرحلة المراهقة.

r-تعد هذه الدراسة الحالية محاولة لمعرفة بعض المتغيرات البيئية والفيزيقية وعلاقتها بالعنف لفهله

المدرسي لدى تلاميذ المرحلة الإعدادية.

الأهمية التطبيقية:

ا-مساعدة القائمين بالعطلية التربوية والتعليمية والمربيين والمعلمين في التعرف على التى خصائص المميزة لذوي سلوك العنف، ومن ثم كيفية تعديل وتقويم سلوك العنف، ومن ثم

تعلم أساليب جديدة للتعامل مع العنف المدرسي.

r-تسعى هذه الدراسة إلى التأكيد على أهمية الاكتثاف المبكر لسلوك العنف المدرسي ومن ثم توعية التلاميذ والآباء والأمهات والمعلمين والقائمين على سير العملية التعليمية بأخطار

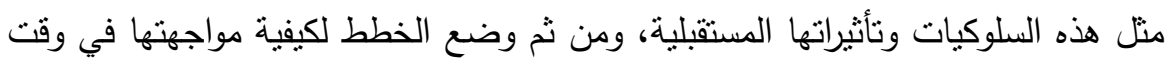
مبكر داخل المجال المدرسي والتعليمي ككل.

r-ستسهم الدراسة في إعطاء المعلمين والأخصائيين النفسيين في المدارس على حد السواء بعض المؤشرات التي تعينهم ونساعدهم في وضع الخطط والآليات والبرامج التربوية والنفسية والبرامج الوقائية والعلاجية التي تساعد في الحد من تأثير هذا السلوك السلبي.

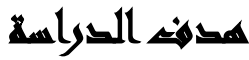

هدفت الدراسة الحالية إلى التعرف على بعض المتغيرات البيئية والفيزيقية وعلاقتها بظاهرة العنف المدرسي لدى تلاميذ المرحلة الإعدادية، وذلك من خلال الأهداف التالية: ا. التعرف على العلاقة بين سلوك العنف المدرسي وبين العلاقات الأسرية والتماسك الأسري والصراع الأسري وحرية التعبير عن المشاعر لدى تلاميذ المرحلة الإعدادية. 
r. التعرف على العلاقة بين سلوك العنف المدرسي والمستوى الاجتماعي والثقافي للأسرة لدى

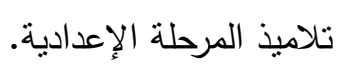

r. التعرف على العلاقة بين سلوك العنف المدرسي والعلاقة بين الأقران لدى تلاميذ المرحلة الإعدادية.

ع. التعرف على العلاقة بين سلوك العنف المدرسي والبيئة المدرسية لدى تلاميذ المرحلة الإعدادية.

ه. التعرف على العلاقة بين سلوك العنف المدرسي والعنف في وسائل الإعلام وتأثيرها على

$$
\text { تلاميذ المرحلة الإعدادية. }
$$

\section{هزوضه الفواسم}

ا-يوجد علاقة ارتباطية بين سلوك العنف الددرسي لدى تلمبذ المرحلة الإعدادية والعوامل البيئية (المناخ المدرسي).

r-يوجد علاقة ارتباطية بين سلوك العنف المدرسي لدى تلاميذ المرحلة الإعدادية والعوامل الفيزيقية (المناخ الأسري). r-يوجد فروق ذات دال إحصائياً بين سلوك العنف المدرسي لدى تلاميذ المرحلة الإعدادية والمستوى الاجتماعي والاقتصادي والتقافي والمهني.

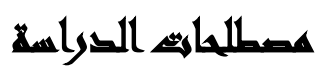

تتحدد مصطلحات الدراسة الحالية في أربع مصطلحات أساسية بمكن تعريفها إجرائباً

$$
\text { على النحو التالي: }
$$

العنف المدرسي: هو سلوك أو فعل يتسم بالعدوانية يصدر عن طرف يتمثل في تلميذ

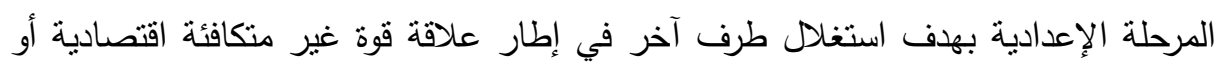
اجتماعية أو سياسية بهدف إحداث أضرار مادية أو معنوية أو نفسية للتلميذ أو المحيطين به.

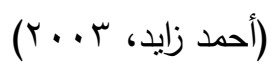


المتغيرات البيئية المدرسية: هي مجموعة المتغيرات المدرسية المحيطة بتلاميذ المرحلة الإعدادية والتي تؤثثر على سلوكياتهم إيجاباً أو سلباً، مثل الإدارة المدرسية، معاملة المعلمين

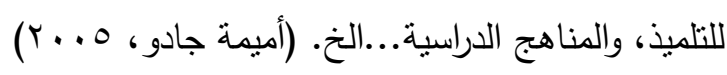

البيئة الفيزيقية: هي النطاق المحيط بالتلميذ ونتمل عدة جوانب منها: العمر، عدد أفراد الأسرة، نرتيب الطفل في الأسرة، الحي والسكن، توافر أنشطة للتلميذ في المدرسة ... الخ.

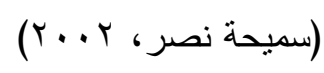

المراهفين: ويقصد بهم التلاميذ ذوي سلوك العنف المدرسي وتتراوح أعمارهم من rا عام إلى ع المراً:

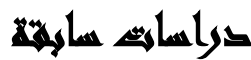

يمكن أن نعرض الدراسات السابقة عن طريق عرض مجموعة من الدراسات التي نتاولت

العنف المدرسي لدى المراهقين وعلاقته بالمتغيرات البيئية والفيزيقية:

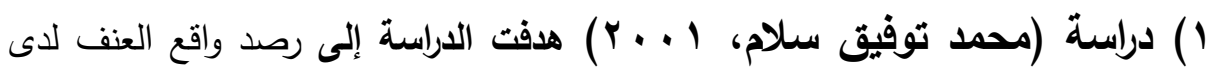
طلبة المدارس الثانوية في مصر، والعوامل المجتمعية، والأسباب المؤدية إلى عنفهم من

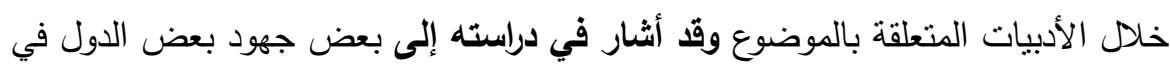

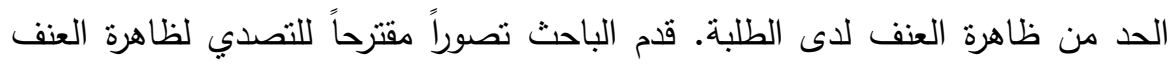

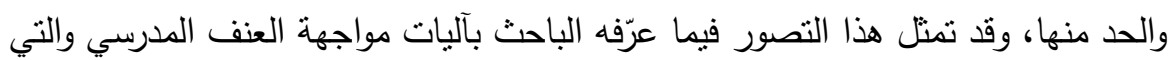

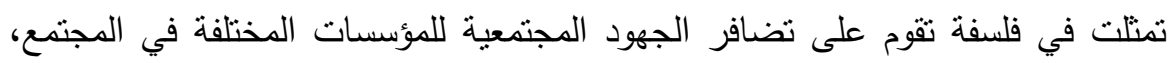
واختبار العناصر القيادية الجيدة والحازمة لإدارة الددرسة وتفعيل دورهم التزبوي في حل لكادل المشكلات السلوكية للطلاب والاهتمام بعملية الإرشاد والتوجيه التربوي.

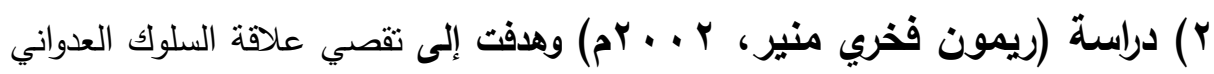

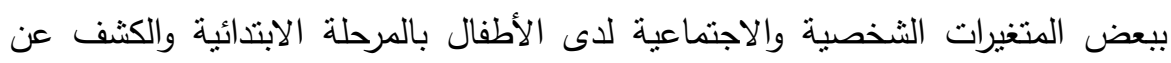

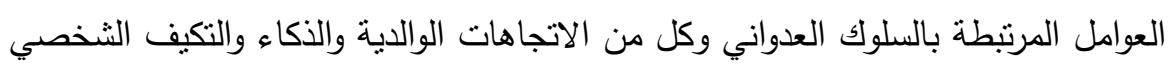
والاجتماعي وترتيب الطفل بين اخوته وحجم الأسرة، المستوى التعليمي للوالدين. وقد

$$
\text { المجلد السادس والأربعون، الجزء الثالث، يونيو } 19 \text { ب. }
$$




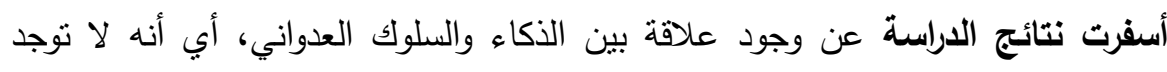

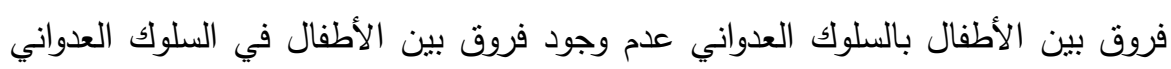
تعزي للمستوى التعليمي للوالدين وحجم الأسرة والتزتيب الولادي.

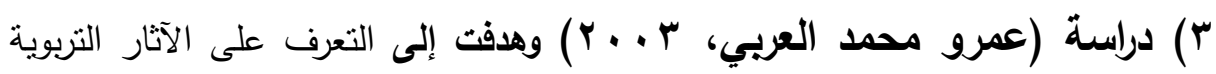

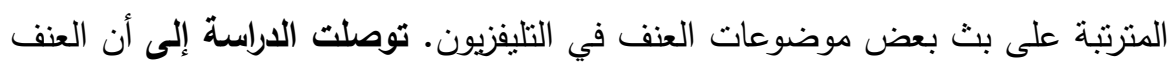

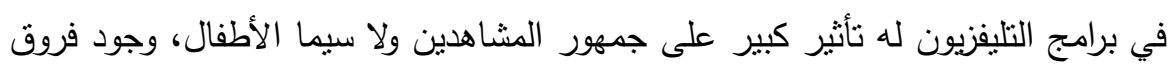

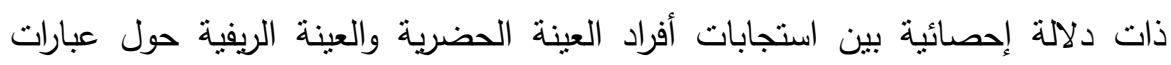

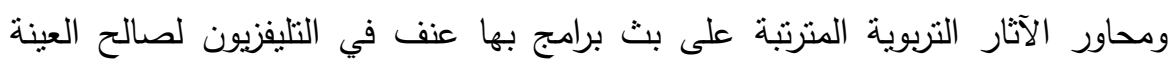
الحضرية. عدم وجود فروق ذات دلالة إحصائية بين استجابات عينة الذكور وعينة الإناث

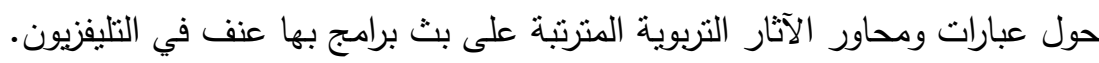

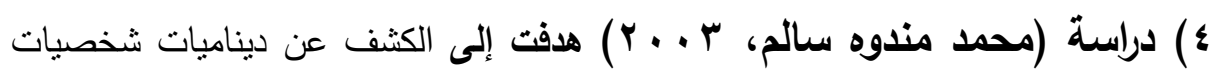

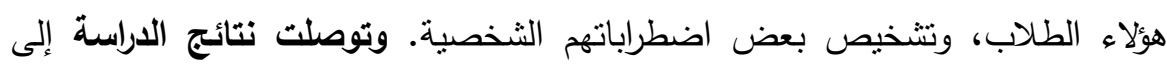

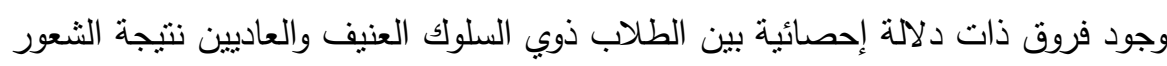

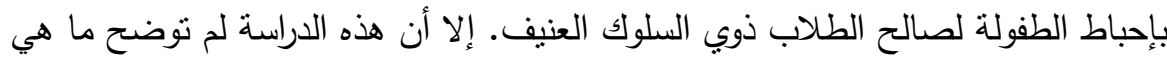
ديناميات السلوك العنيف لدى الطلاب.

•) دراسة (الحسين ماثير، ؟ . . ب ) درست هذه الدراسة الخصائص السلوكية العنيفة

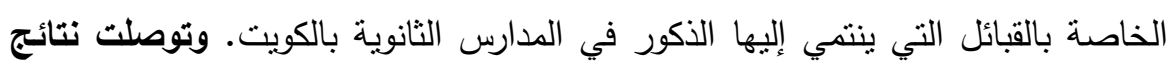

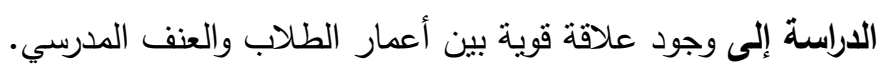

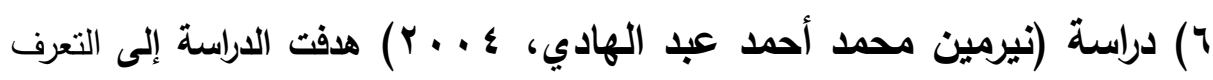

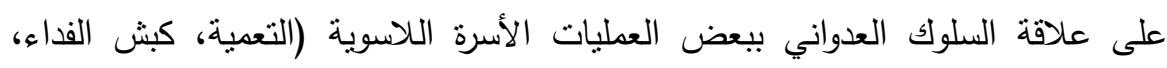

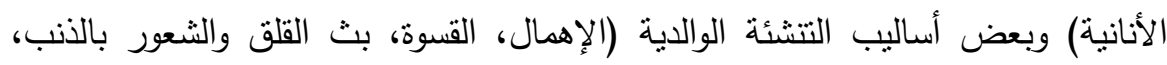

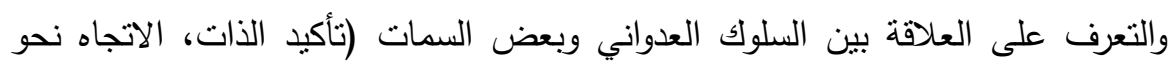

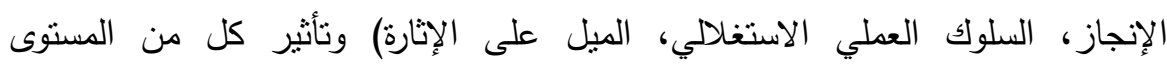

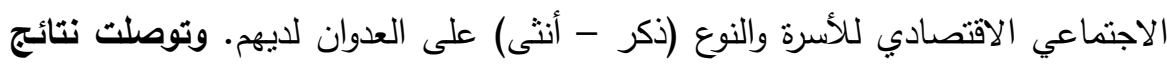


الاراسة إلى توصلت الدراسة على أن هناك علاقة ارتباطية بين العمليات الأسرية اللاسوية والسلوك العدواني لاى الطلاب، كما أن هناك علاقة طردية بين تدني المستوى الاجتماعي الأي والاقتصادي وسلوك العنف لدى الطلاب.

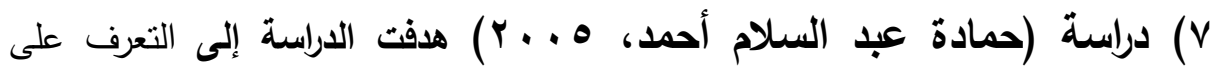
الاتجاهات والنظريات المفسرة للعنف في مدارس التعليم الثانوي بالولايات المتحدة الأمريكية. وأظهرت نتائج الدراسة الميدانية أن السبب المباشر في ظاهرئ لأهرة انتشار العنف في مدارس التعليم الثانوي يرجع إلى عوامل البيئة الداخلية، سوء التنشئة الاجتماعية، النزاع

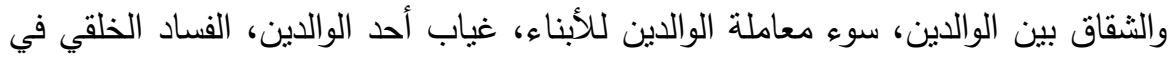

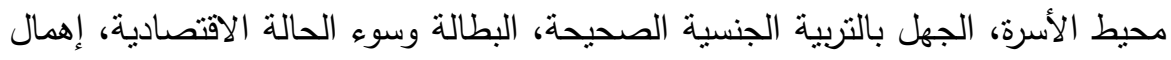

$$
\text { الوالدين دوره في رعاية الأسرة. }
$$

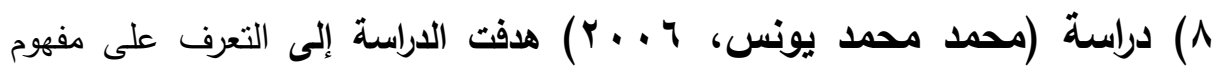
العنف المدرسي، وطبيعة العنف المدرس معرباً أو أثنكاله، وتحليل أبعاد هذه المشكلة

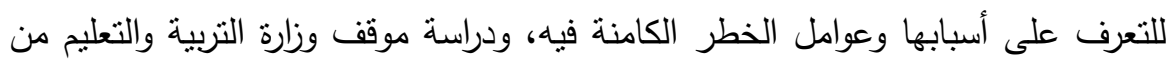

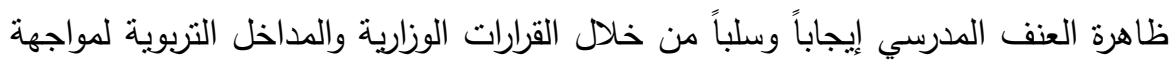

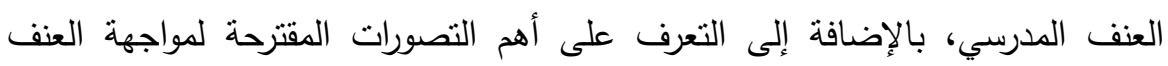

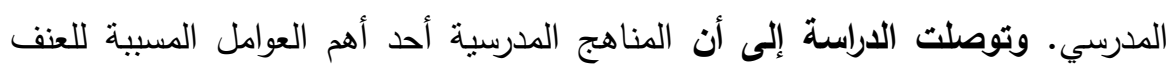

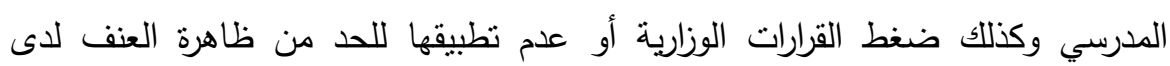
الطلاب في المراحل التعليمية المختلفة.

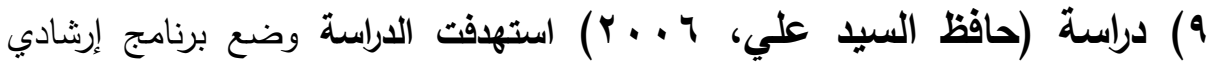

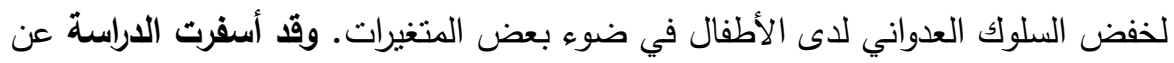
وجود فروق بين الجنسين في السلوك العدواني وهي أن في السلوك المادي والسلبي وكان

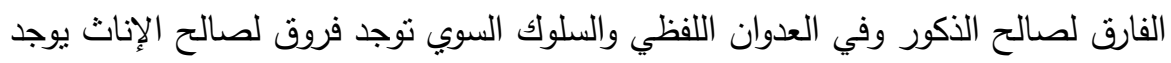
ارتباط بين الازدحام داخل الفصل بالعدوان المادي واللفظي بأنها لا ترتبط بالعدوان السلبي

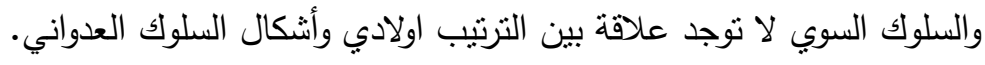

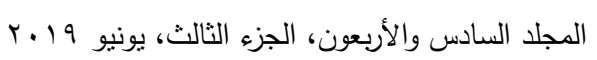


تعقيب على الدراسات السابقة: ساهم استعراض الباحثون للارراسات السابقة في مساعدتها على تحديد النقطة التي ستبدأ منها في البرنامج الحالي للاراسة:

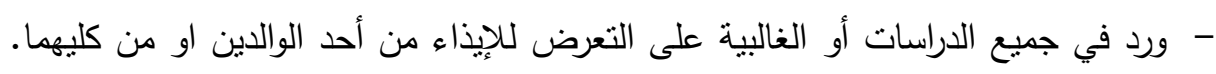

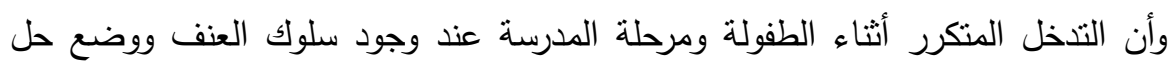
لمواجهة هذا السلوك يؤدي إلى نتائج جيدة في التقليل من هذه الظاهرة.

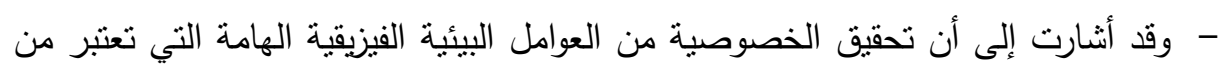

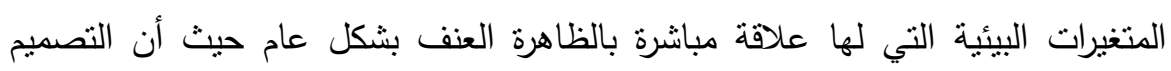

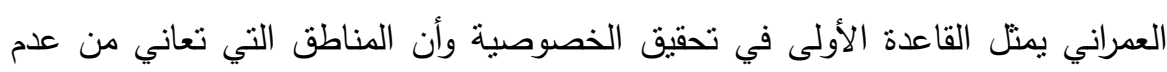

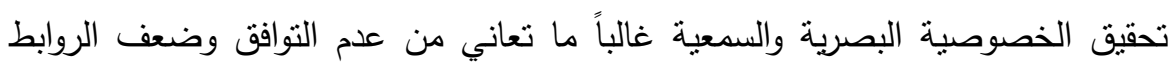
الاجتماعية بين أفرادها.

- واتفقت معظم الدراسات أيضاً على أن دور المدرسة لا يقتصر فقط على تلقي الخبرات والتعليم بل أنها تقوم بدور بالغ الأهية في تتكيل سلوك وشخصية التلاميذ وإنماء

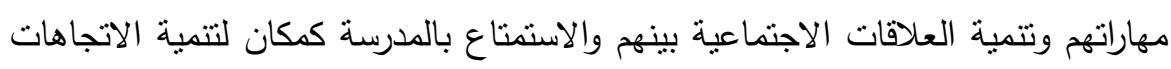

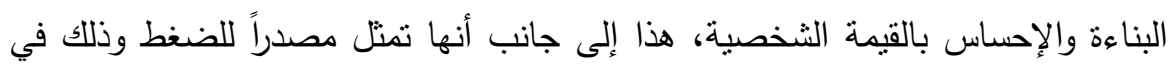

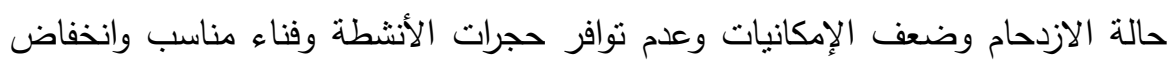
مستوى الفصول والحمامات والإضاءة والتهوية وارتفاع مستوى الضوضاء.

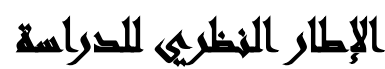

مفهوم العنف: فيعرف العنف بأنه سلوك إيذائي قوامه إنكار الآخرين كقيمة ممانلة للأنا أو

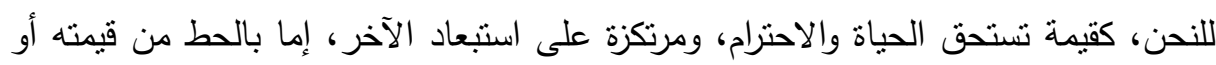
تحويله إلى تابع أو بنفيه خارج الساحة أو بتصفيته معنويا أو جسديا. ويعرف أيضا بأنها

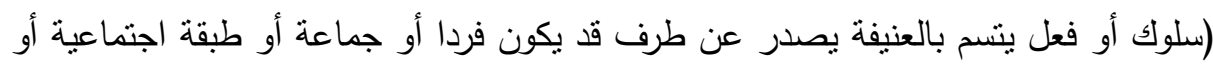
دولة بهدف استغلال طرف آخر في إطار علاقة قوة غير منكافئة اقتصادية أو اجتماعية أو فئون

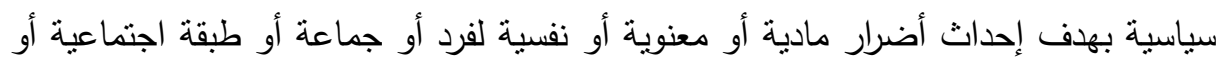

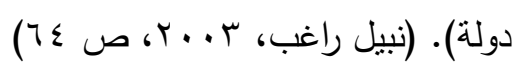


مفهوم المراهقة: "الاقتراب من النضج الجسمي والعقلي والنفسي والاجتماعي"، ولكنه ليس

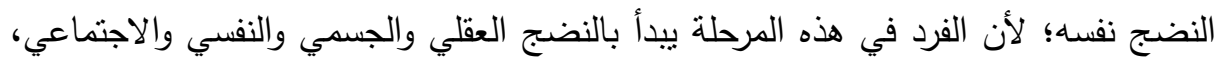

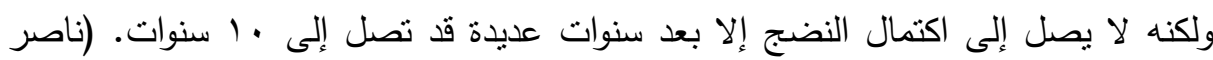

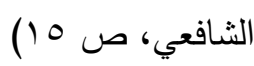
مفهوم العنف المدرسي: يرى (مصطفى محمد علي، 10 ب) أن المقصود منه ما يجري

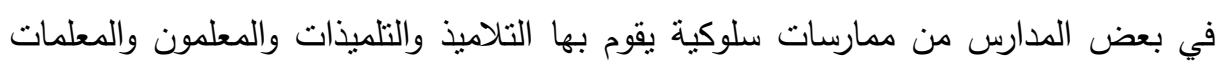
نتيجة الغضب وتزايد الانفعال ويترتب عن ذلك استخدام اللكم والضرب باستعمال الآلات الحادة والعصي وأحيانا بالسلاح. مفهوم البيئة الفيزيقية: تمثل البيئة الفيزيقية الإطار الذي يتم فيه التعلم وهي من الأمور المهمة في زيادة الفاعلية، ويعبر عنها باستجابة التلميذ اللفظية التي تعبر عن مجموع تقديراته

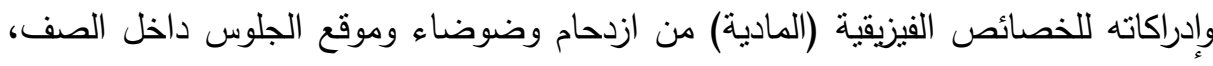

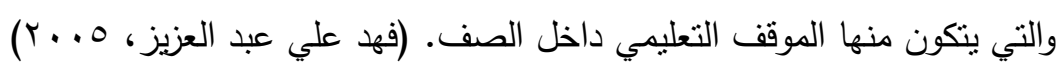
النظريات المفسرة للعنف: نظرية الضغط البيئي: وهذه النظرية نرى أن الضغوط البيئية المختلفة سواء كانت ازدحام أو ضوضاء أو تلوث وخلافه من ضغوط البيئية الفيزيقية، فهذه الضغوط إنغاذ إذا زادت عن مقدار

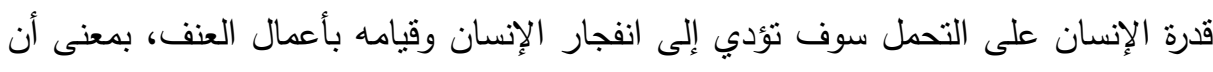

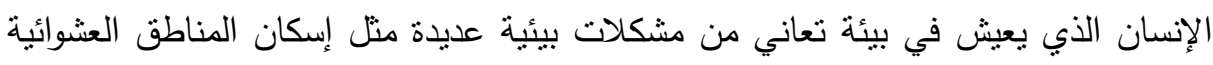
والمختلفة التي تعاني من الازدحام وسوء حالة المسكن ونقص الخصوصية ونقص الخصني الخدمات والمرافق هذه البيئة تدفع الإنسان دفعاً للعنف ومن الطبيعي أن يوجه هذا العنف العنف للضعفاء وفي

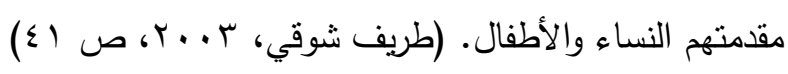

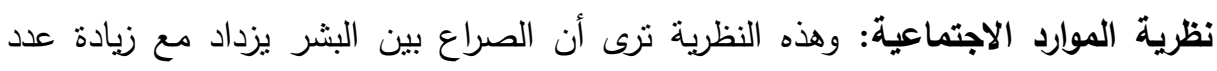

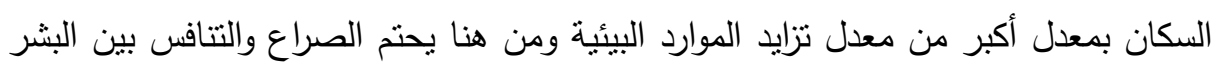
حول الموارد المحدودة ويتحول إلى عنف ومن ثم يمكن النظر لمشكلة تزايد السكان نتيجة تزايد

$$
\text { المجلد السادس والأربعون، الجزء الثالث، يونيو } 9 \text { 1 بـ }
$$


اليد في أي بلد موارده محدودة فتسبب ظهور العنف نتيجة للصراع حول الموارد المحدودة.

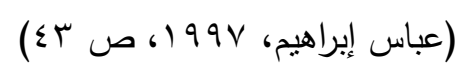
نظرية الإحباط: وتتص هذه النظرية على أن البيئة الني تتسبب في الإحباط للفرد تدفعه نحو

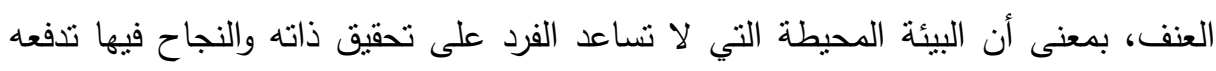

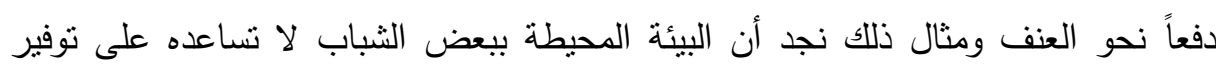

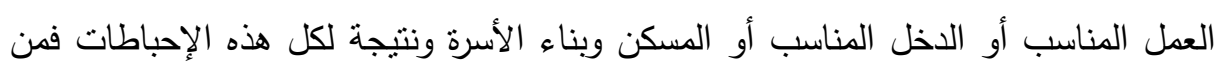

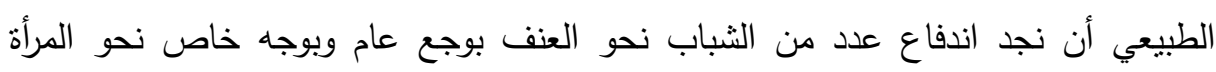

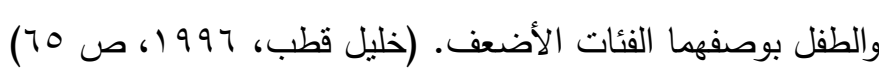

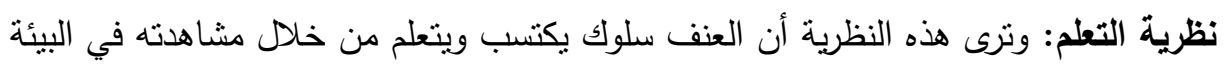

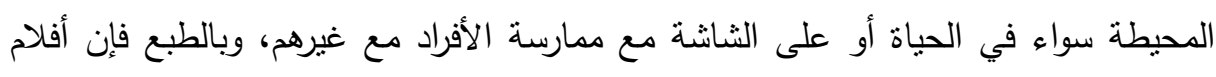

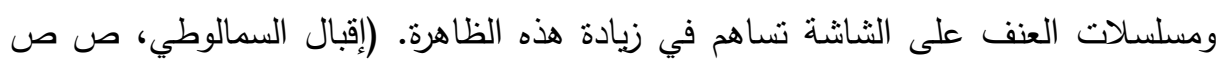

نظرية التحليل النفسي: يرجع فرويد العنف إما لعجز (الأنا) عن تكييف النزاعات الفطرية

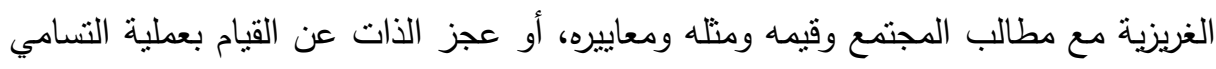

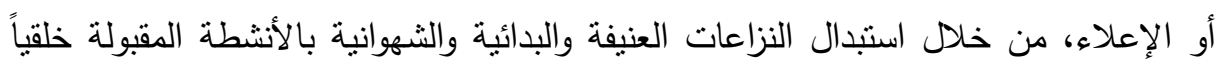

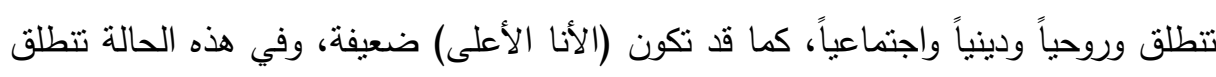

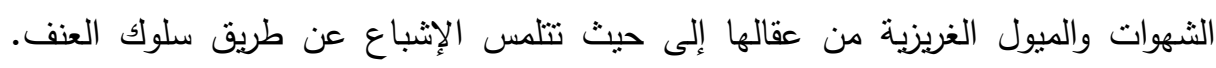

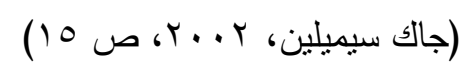

\section{الاجبراعاهي المنهبيه التصراسة}

منهج الدراسة: تعتد هذه الدراسة على الدنهج الوصفي الارتباطي باعتباره أكثر المناهج

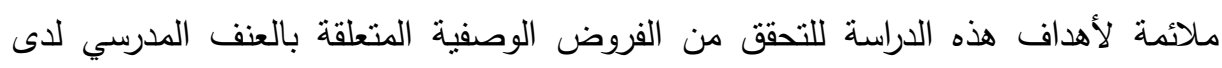
المراهقين وعلاقته ببعض المتغيرات البيئية والفزيقية. 


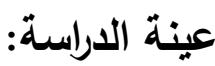

خصائص العينة: تكونت عينة الدراسة الوصفية من (..r) تلميذ من تلاميذ المرحلة

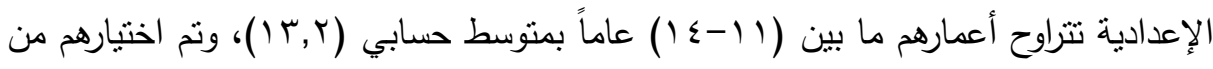

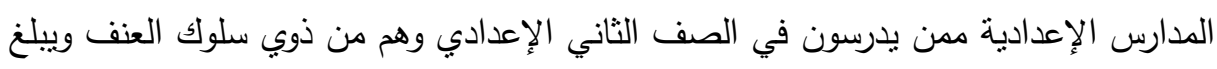

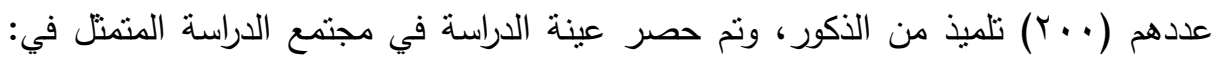

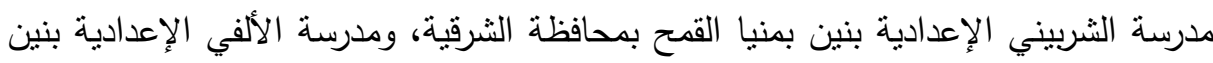

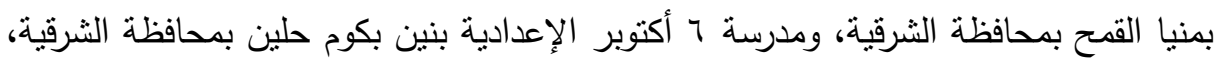

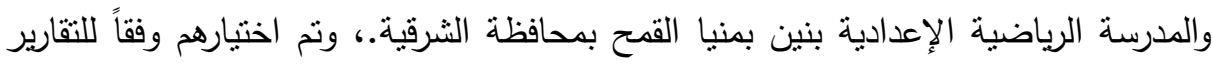

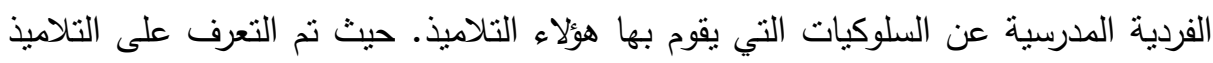
ذوي سلوك العنف من خلال ملاحظات المعلمين والمرشدين النفسيين في المدرسة وسجلات الإرشاد التزبوي بالمدرسة مع الاستعانة بملاحظات معلمي الصفوف. وقد نم الختيار العينة بطريقة قصدية.

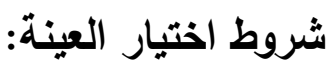

1-أسباب اختيار العينة من الذكور: تم اختيار العينة من الذكور لأن العنف الددرسي أكثر

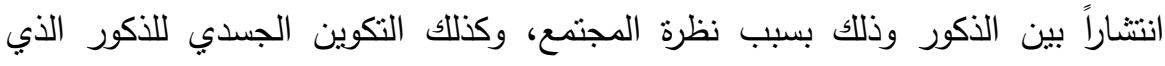
يدفعهم لممارسة العنف بشكل ملحوظ وبمعدلات مرتفعة، وذلك على العكس من الإناث، فلإناث يستخذمن أساليب عنف غير ظاهرة يصعب اكتثافها حتى إن المعلمين وغيرهم من الكبار غالباً لا يتمكنون من ملاحظتها وكثفها. r-أسباب اختيار هذه الفئة العمرية: تم اختيار هذه الفئة العمرية لأنها تعتبر أخطر المراحل

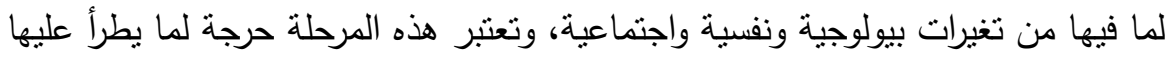

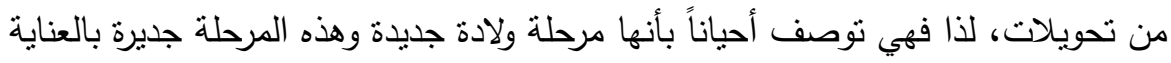
والدراسة. 
أدوات الاراسةة: للتحقق من صحة فروض الدراسة استخدم الباحثون الأدوات التالية: 1-مقياس العنف المدرسي (إعداد: مي عبد المنعم عبد الفتاح الميتكناني، 9 ( • ب). r-مقياس المناخ البيئي والفيزيقي للمراهقين (إعداد: مي عبد المنعم الميتكناني، 9 ( • ب). r-مقياس المستوى الاجتماعي الاقتصادي النقافي المطور (إعداد: محمد محمد بيومي خليل، . (r...

صدق المقياسين (مقياس العنف الددرسي، مقياس المناخ البيئي والفيزيقي للمراهقين): قام

الباحثّن بتقنين فقرات المقياسين، وذلك للتأكد من صدقها.

صدق المحكمين: عرض الباحثون المقياسين على مجموعة من الخبراء في مجال

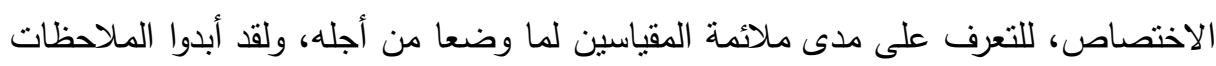

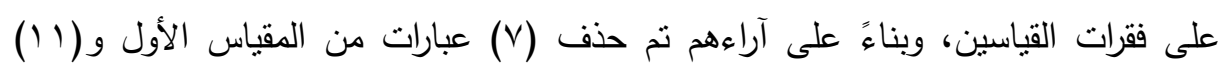

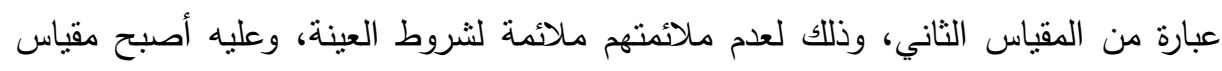

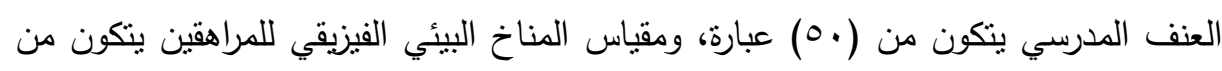

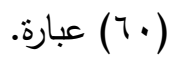

الأساليب الإحصائية المستخدمة في الدراسة: وللتحقق من صحة فروض الدراسة استخدم الباحثون أساليب المعالجة الإحصائية التالية: - معامل ألفا كرونباخ لحساب ثبات أدوات الدراسة. - - استخدام المتوسط الحسابي، الانحراف المعياري.

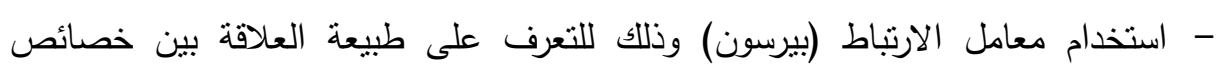

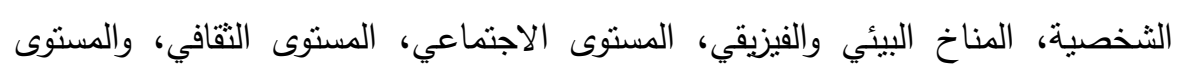

$$
\text { الاقتصادي لعينة الدراسة. }
$$

- اختبار T.Test التبين دلالة الفروق بين متغيرات الدراسة.

صدق الاتِّساق الداخلي: نم حساب معاملات ارتباط كل بعد من أبعاد المقياس بالدرجة الكلية

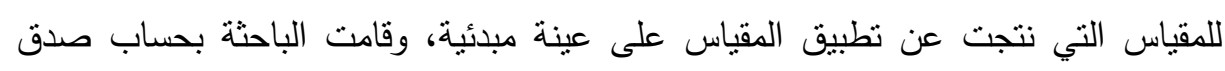
الاتُّاق الداخلي ومعامل الارتباط المصحح لمقاييس الدراسة كالآتي: تلمبئ 
جدول رقم(1): صدق الاتُّاق الداخلي لأبعاد المقاييس (مقياس العنف المدرسي - مقياس

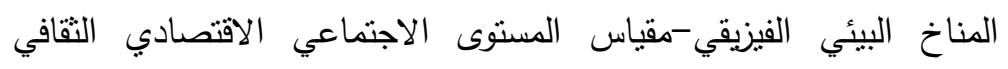

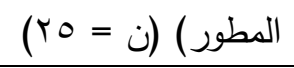

\begin{tabular}{|c|c|c|c|c|}
\hline معامل الارتباط & إجمالي المقياس & \multicolumn{3}{|c|}{ أبعاد المقياس } \\
\hline \multirow{2}{*}{$\cdot, 94$} & $($ (**)!, ^V・ & معامل ارتباط بيرسون & \multirow{2}{*}{\multicolumn{2}{|c|}{ مقياس العنف المدرسي }} \\
\hline & $\cdot, \ldots 1$ & الدلالة المعنوية & & \\
\hline \multirow{2}{*}{$\cdot, 9 \leqslant$} & $(* *) \cdot, \wedge \vee \wedge$ & معامل ارتباط بيرسون & المناخ & \multirow{4}{*}{ المقياس البيئي } \\
\hline & $\cdot, \cdots 1$ & الدلالة المعنوية & 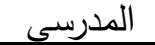 & \\
\hline \multirow{2}{*}{$\cdot$, A V } & $(* *) \cdot, \vee 09$ & معامل ارتباط بيرسون & \multirow{2}{*}{ الأسرين } & \\
\hline & $\cdot, \cdots 1$ & الدلالة المعنوية & & \\
\hline \multirow{2}{*}{$\cdot, \wedge \wedge$} & $(* *) \cdot, \wedge \ldots$ & معامل ارتباط بيرسون & \multirow{2}{*}{ الاجتماعتي } & \multirow{8}{*}{ 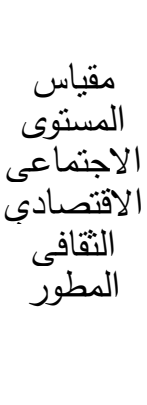 } \\
\hline & $\cdot, \ldots 1$ & الدلالة المعنوية & & \\
\hline \multirow{2}{*}{$\cdot, 9 \varepsilon$} & $(* *) \cdot, \wedge 9 \leq$ & معامل ارتباط بيرسون & \multirow{2}{*}{ الاقتصنادي } & \\
\hline & $\cdot, \ldots 1$ & الدلالة المعنوية & & \\
\hline \multirow{2}{*}{$\cdot, 97$} & $(* *) \cdot, 9 r Y$ & معامل ارتباط بيرسون & \multirow{2}{*}{ المستوي } & \\
\hline & $\cdot, \ldots 1$ & الدلالة المعنوية & & \\
\hline \multirow{2}{*}{ •, $7 \leqslant$} & $(* *) \cdot \leq \vee\urcorner$ & معامل ارتباط بيرسون & \multirow{2}{*}{ المسنتوى } & \\
\hline & $\cdot, \cdots 1$ & الدلالة المعنوية & & \\
\hline
\end{tabular}

من جدول صدق الاتُّاق الداخلي السابق لأبعاد المقاييس (مقياس العنف المدرسي مقياس المناخ البيئي الفيزيقي- مقياس المستوى الاجتماعي الاقتصادي الثقافي المطور

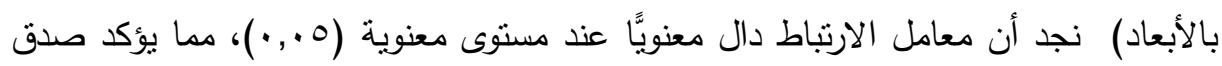

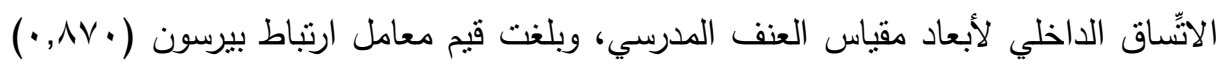

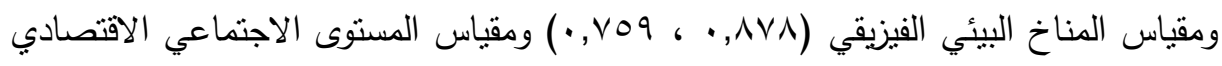

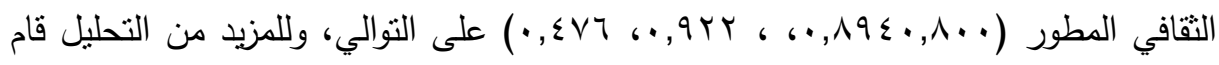

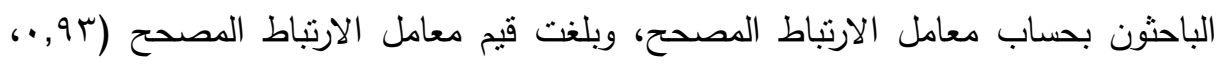
§ 9, •، AV, •، A المدرسي، المناح الأسري، المستوى الاجتماعي، المستوى الاقتصادي، المستوى الثقافي،

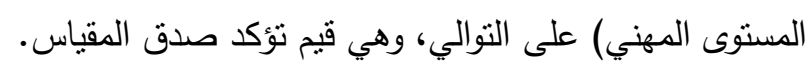




\section{مقياس العنف المدرسي (إعداد الباحثون):}

ثبات المقياس: حساب ثبات المقياس: للتحقق من ثنات المقياس استخدم الباحثون معادلة ألفا كرونباخ (Alpha Cronbach)، ويوضح الجدول الآتي معاملات الثبات الناتجة باستخدام

هذه المعادلة.

جدول رقم(ץ): معاملات حساب الثبات لمقياس العنف المدرسي

\begin{tabular}{|c|c|c|c|}
\hline مستوى الدلالة & معامل الثبات & طرق حساب الثبات & ? \\
\hline., .1 & $\cdot, 7 \pi 9$ & التجزئة النصفية (فردى / زوجى) & 1 \\
\hline$\cdot, ., 1$ & $\cdot, \times 70$ & معامل ألفا كرونباخ & T \\
\hline
\end{tabular}

اتضح من الجدول السابق أن معاملي الثبات وبرغم اختلاف طريقتي حسابهما إلا أن

أنهما دالين ومرتفعين. مما يشير إلى تمتع المقياس بثبات مقبول قيم معاملات الثبات (مقياس

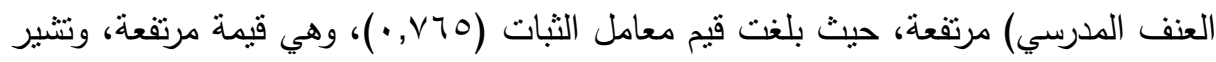

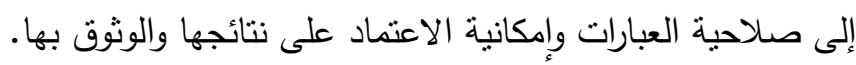

صدق المقياس:

\begin{tabular}{|c|c|c|}
\hline إجمالي المقياس & \multicolumn{2}{|c|}{ أبعاد المقياس } \\
\hline$(* *) \cdot, \wedge \vee \cdot$ & معامل ارتباط بيرسون & \multirow{2}{*}{ مقياس العنف المدرسي } \\
\hline$\cdot, \cdots 1$ & الدلالة المعنوية & \\
\hline
\end{tabular}

من جدول صدق الاتُّاق الداخلي السابق لأبعاد المقاييس (مقياس العنف المدرسي) نجد

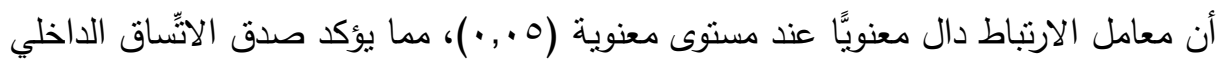

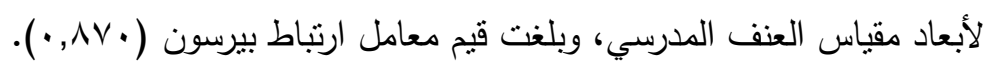

ثبات المقياس: قياس الثبات ومعامل الثبات Reliability Coefficient حساب ثبات المقياس: للتحقق من ثبات المقياس لإمكانية الاعتماد على نتائج المقاييس

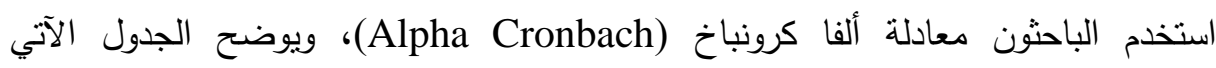
معاملات الثبات الناتجة باستخدام هذه المعادلة. 
جدول رقم(r): ثبات العبارات لأبعاد المقاييس (مقياس العنف المدرسي) (ن = ب ب)

\begin{tabular}{|c|c|c|}
\hline قَيمة ألفا & عدد العبارات & آبعاد المقياس \\
\hline$\cdot, \vee \vee 0$ & 0. & العنف المدر \\
\hline
\end{tabular}

اتضح من الجدول السابق أن قيم معاملات الثبات (مقياس العنف المدرسي) مرتفعة،

حيث بلغت قيم معامل الثبات (VT0, •) )، وهي قيمة مرتفعة، وتشير إلى صلى صلاحية العبارات

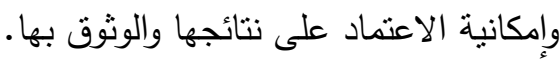
مقياس المناخ البيئي الفيزيقي للمراهقين: وصف المقياس: تتاول المتوف المقياس بعدين هما المناخ

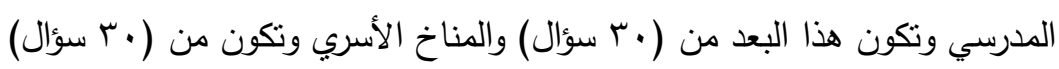
ثبات المقياس: للتحقق من ثبات المقياس لإمكانية الاعتماد على نتائج المقاييس استخدم الباحثون معادلة ألفا كرونباخ (Alpha Cronbach)، ويوضح الجدول ثبات الآتي معاملات التبات التبات الناتجة باستخدام هذه المعادلة وطريقة التجزئة النصفية كما يشير اليها الجدول جدول رقم(ء): معاملات حساب الثبات لمقياس المناخ البيئي والفيزيقي للمراهقين

\begin{tabular}{|c|c|c|c|}
\hline مستوى الدلالة & معامل الثبات & طرق حساب الثبات & م \\
\hline$\cdot, \cdot, 1$ & $\cdot, V O Y$ & التجزئة النصفية (فردى /زوجى) & -1 \\
\hline$\cdot, ., 1$ & $\cdot$, , АTा & معامل ألفا كرونباخ & $-Y$ \\
\hline
\end{tabular}

اتضح من الجدول السابق أن معاملي الثبات وبرغم اختلاف طريقتي حسابهما إلا أن أنهما دالين ومرتفعين. مما يشير إلى تمتع المقياس بثنات مقبول. صدق المقياس:

\begin{tabular}{|c|c|c|c|}
\hline إجمالي المقياس & \multicolumn{3}{|c|}{ أبعاد المقياس } \\
\hline$(* * *) \cdot, \wedge \vee \wedge$ & معامل ارتباط بيرسون & & \\
\hline$\cdot, \ldots 1$ & الدلالة المعنوية & المناخ المدرسي & مقياس المناخ البيئي \\
\hline$(* *) \cdot, \vee 09$ & معامل ارتباط بيرسون & & فيزيقي \\
\hline$\cdot, \cdots 1$ & الدلالة المعنوية & $z$ & \\
\hline
\end{tabular}

من جدول صدق الاتُّاق الداخلي السابق لأبعاد المقاييس (مقياس العنف الددرسي) نجد

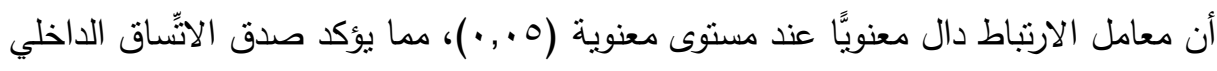

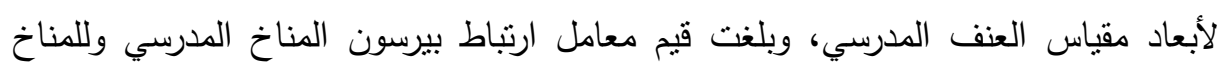

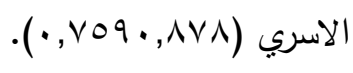


Reliability Coefficient ثيّات المقياس: قياس الثبات ومعامل الثبات حساب ثبات المقياس: للتحقق من ثبات المقياس لإمكانية الاعتماد على نتائج المقاييس

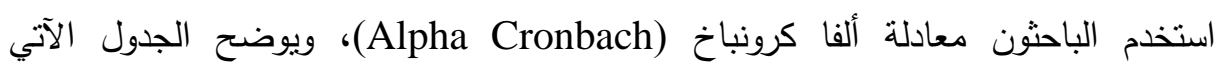
معاملات الثبات الناتجة باستخدام هذه المعادلة.

\begin{tabular}{|c|c|c|c|}
\hline قيمة ألفا & عدد العبارات & \multicolumn{2}{|c|}{ آبعاد المقياس } \\
\hline 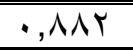 & $r$. & المناخ المدرسي & \multirow{3}{*}{ مقياس العنف المدرسي } \\
\hline$\cdot, \vee \vee \vee q$ & $r$. & المناخ الاسري & \\
\hline •,人тT & 7. & إجمالى المقياس & \\
\hline
\end{tabular}

اتضح من الجدول السابق أن قيم معاملات الثبات (مقياس العنف المدرسي) جميعها قيم

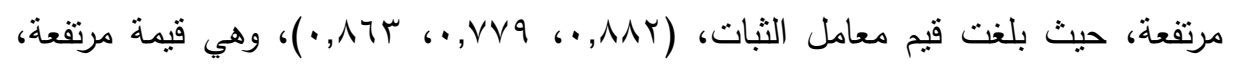

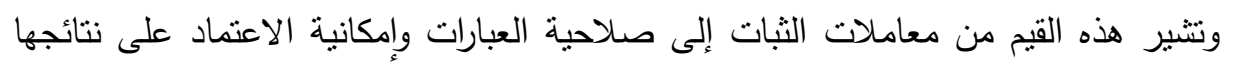
والوثوق بها.

مقياس المستوى الاجتماعي الاقتصادي الثقافي المطور: (إعداد: محمد محمد بيومي خليل، $\cdot(r \cdot \cdots$

\section{وصف المقياس:}

1-المستوى الاجتماعي: وتتاول ست أسئلة السؤال الأول المستوى الاجتماعي للأسرة والسؤال

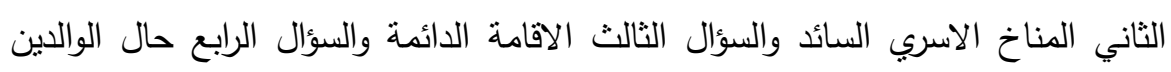
والسؤال الخامس العلاقات الاسري والسؤال السادس حجم الأسرة

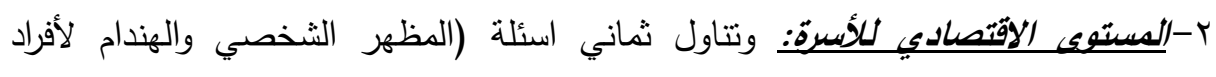

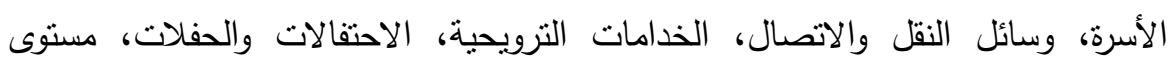
الأجهزة والأدوات المنزلية، مستوى السكن، مستوى السكن، مستوى الأثاث، التغذية والرعاية الصحية، الصناء

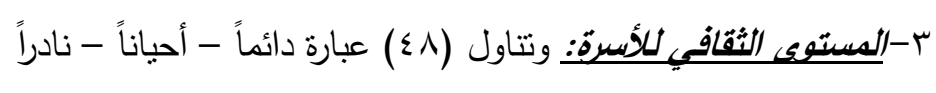




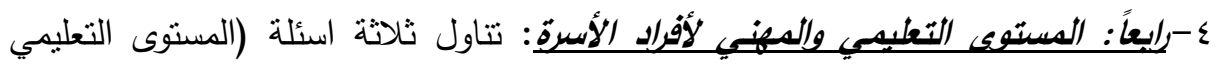

لجميع أفراد أسرتي، اتفاق الأسرة على التعليم ومستوى الخدمات التعليمية، مهن أفراد

أسرتلك العاملين فقط)

تصحيح المقياس: بالنسبة لأسئلة المستوى الاجتماعي: المستوى الاقتصادي للأسرة: المستوى

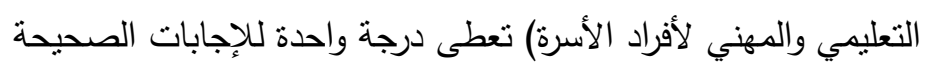
1. اما المستوى الثقافي للأسية: اعطاء (صفر ) للإجابة (ابدا) ودرجة (واحد) للإجابة (احيانا) ودرجة (اثثين) للإجابة (كثيرا) وذلك على النحو التالي:

\begin{tabular}{|c|c|}
\hline الارجة الكلية & المستوى \\
\hline 7 & الاجتماعي \\
\hline$\Lambda$ & الاقتصنادي \\
\hline 97 & الثقافي \\
\hline$\mu$ & المهزخ \\
\hline
\end{tabular}

صدق المقياس: حسب الباحثون الصدق التلازمي المرتبط بالمحك، وذلك بحساب معامل ارتباط بيرسون بين درجات أفراد العينة على مقياس المناخ البيئي والفيزيقي للمراهقين.

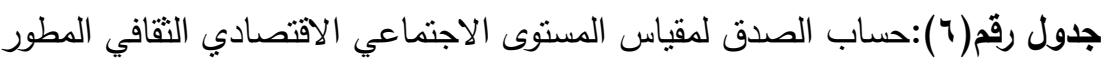

\begin{tabular}{|c|c|c|c|c|}
\hline مستوى الدلالة & معامل ارتباط بيرسون & ن & المقياس & م \\
\hline .1 & $(* *) \cdot, \wedge$ & ro & الاضقصاس المستوى التقافي المطماعى & 1 \\
\hline
\end{tabular}

من الجدول السابق يتضح صدق الاتُّاق الداخلي السابق لكقياس المستوى الاجتماعي

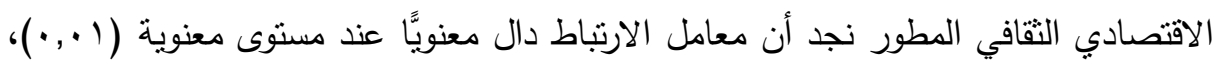

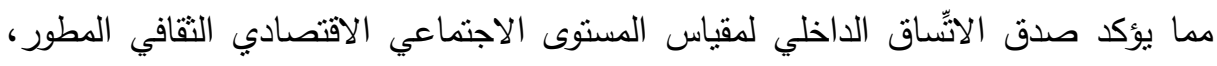
وبلغت قيم معامل ارتباط بيرسون ( • . ی, •). 
جدول رقم(V): صدق الاتُّاق الداخلي لأبعاد الدقاييس (مقياس المستوى الاجتماعي

\begin{tabular}{|c|c|c|c|}
\hline إجمالى المقياس & $\left(r_{0}=\dot{u}\right)$ & لاقتصادي الثقافي المد أبعاد المقيا & \\
\hline$(* * *) \cdot \wedge \ldots$ & معامل ارتباط بيرسون & \multirow{2}{*}{ المستوى الاجتماعي } & \multirow{8}{*}{ الالإنماعتىى النقادي } \\
\hline$\cdot, \cdots 1$ & الدلالة المعنوية & & \\
\hline$(* *) \cdot, \wedge 9 \varepsilon$ & معامل ارتباط بيرسون & \multirow{2}{*}{ المستوى الاقتصادي } & \\
\hline$\cdot, \cdots 1$ & الدلالة المعنوية & & \\
\hline$(* *) \cdot, 9 Y Y$ & معامل ارتباط بيرسون & \multirow{2}{*}{ المستوي الثقافي } & \\
\hline$\cdot, \cdots 1$ & الدلالة المعنوية & & \\
\hline$\left.(* *) \cdot \sum \vee\right\urcorner$ & معامل ارتباط بيرسون & \multirow{2}{*}{ المستوى المهني } & \\
\hline$\cdot, \cdots 1$ & الدلالة المعنوية & & \\
\hline
\end{tabular}

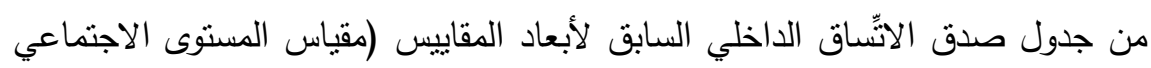

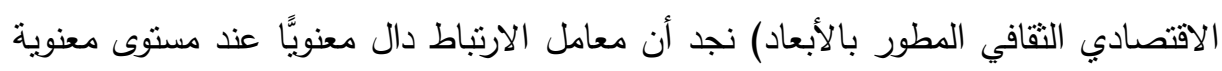

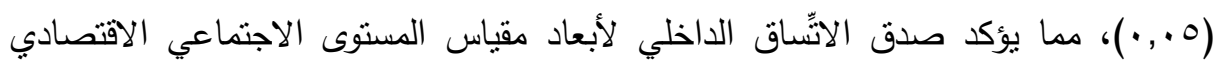

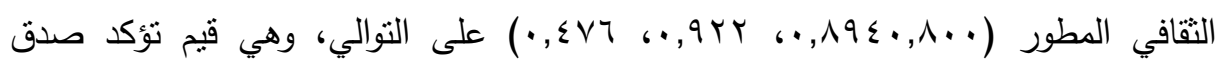
المقاييس. ثبات المقياس: ثبات العبارات لأبعاد المقاييس (مقياس المستوى الاجتماعي الاقتصادي

\begin{tabular}{|c|c|c|c|}
\hline قيمة آلفا & عدد العبارات & \multicolumn{2}{|c|}{ آبعاد المقياس } \\
\hline$\cdot, \mathrm{VOV}$ & 7 & المستوي الاجتماعي & \multirow{4}{*}{ الاقتصاس المستوي الثقافي الاجنماعي } \\
\hline$\cdot, \wedge \wedge \uparrow$ & $\Lambda$ & المستوى الاقتصادي & \\
\hline$\cdot, \vee \vee 0$ & $\varepsilon \Lambda$ & المستوي الثقافي & \\
\hline . & $\mu$ & المستوى المهنى & \\
\hline
\end{tabular}

اتضح من الجدول السابق أن قيم معاملات الثبات (مقياس المستوى الاجتماعي

الاقتصادي الثقافي المطور بالأبعاد) جميعها قيم مرتفعة، حيث بلغت قيم معامل الثبات

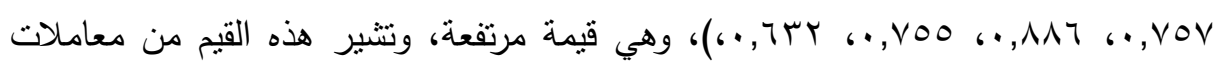

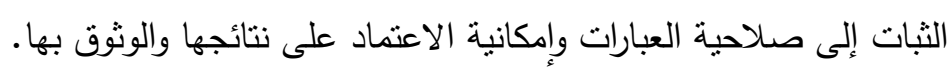




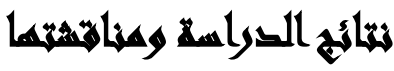

أولاً: القرض الأول: معاملات الارتباط بين درجات عينة الطلاب على مقياس العنف المدرسي والعوامل البيئية

\begin{tabular}{|c|c|c|}
\hline الدلالة المعنوية & سلوك العنف المدرسى & \\
\hline$\cdot, \cdot, 1$ & $(* *) \cdot, r V V$ & الدرجة الكلية للعوامل البيئية \\
\hline
\end{tabular}

تتشير نتائج الجدول السابق إلى تحقق صدق الفرض الأول حيث وجد ارتباط موجب دال

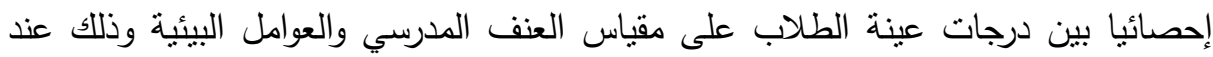
مستوى دلالة ا.,.,. مناقشة نتيجة الفرض الأول: والتي كانت نتيجتها وجود ارتباط موجب دال إحصائياً بين درجات عينة الطلاب على مقياس العنف الددرسي والعوامل البيئية، وقد اتفقت معه دراسة

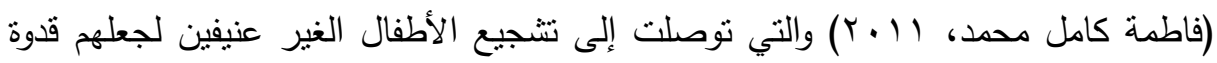
أمام الأطفال الآخرين. ضمن المرحلة الواحدة يكون العنف لدى الأطفال الفاقدين لأحد الوالدين

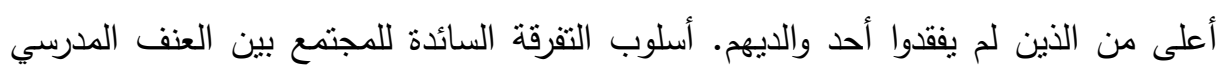

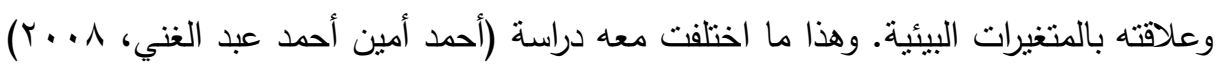

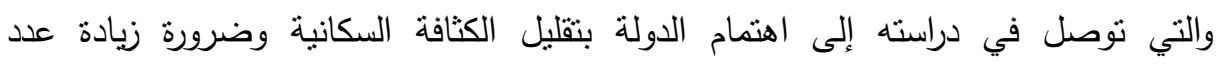
الاخصائيين الاجتماعيين بالمدارس، وعلى الإعلام بالاهتمام بتتمية الاتجاهات الإيجابية

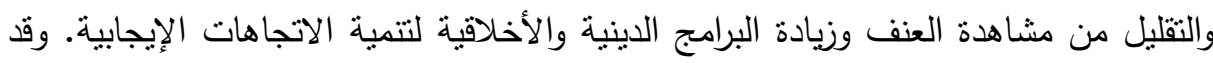

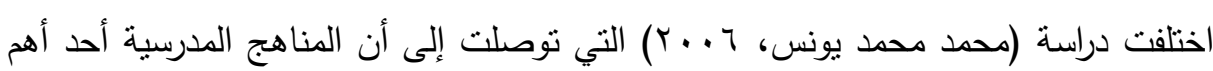
العوامل المسببة للعنف المدرسي. ثانيا: الفرض الثاني: معاملات الارتباط بين درجات عينة الطلاب على مقياس العنف المدرسي والعوامل الفيزيقية

\begin{tabular}{|c|c|c|}
\hline الدلالة المعنوية & سلوك العنف المدرسي & \\
\hline,$+ \ldots 1$ & $(* *) \cdot, 09 \Sigma$ & الدرجة الكلية للعوامل الفيزيقية \\
\hline
\end{tabular}


تتثير نتائج الجدول السابق إلى تحقق صدق الفرض الأول حيث وجد ارتباط موجب دال

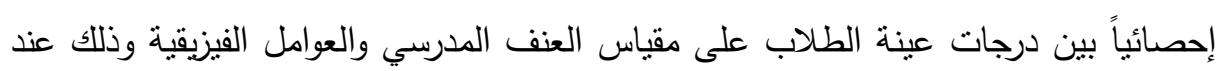

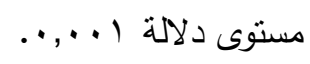

مناقشة نتيجة الفرض الثاني: والتي كانت نتيجتها وجود ارتباط موجب دال إحصائباً بين

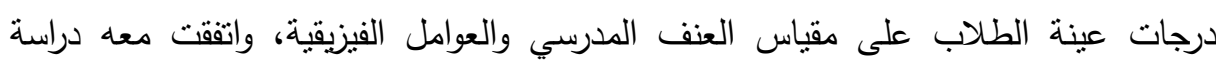

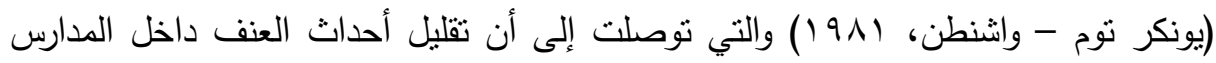

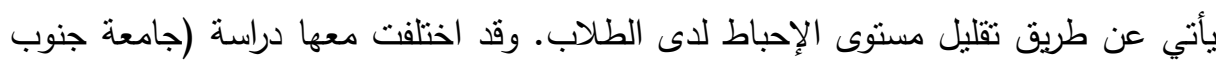
الوادي، مجلة مصر التربوية 991 (1) والتي توصلت إلى ألى أن اهتمام وسائل الإعلام وتقديم

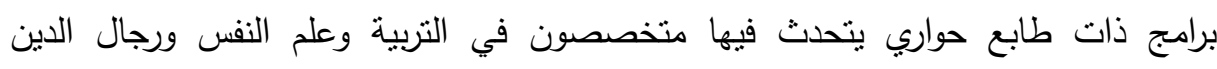

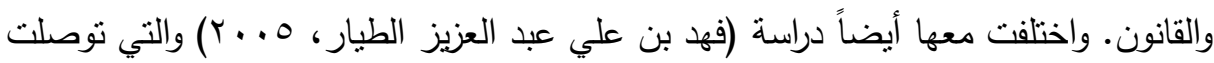

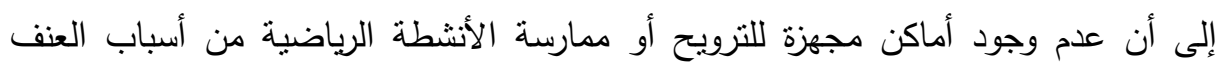
المدرسي ويرجع ذلك إلى عدم التعاون بين الطلاب والمدرسين. ثالثاً: الفرض الثالث: معاملات الارتباط بين درجات عينة الطلاب على مقياس العنف

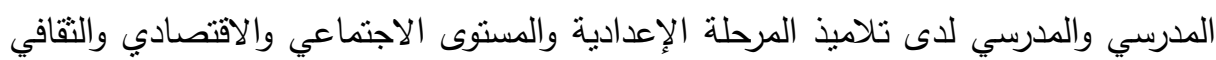

\begin{tabular}{|c|c|c|}
\hline الدلالة المعنويـة & سلوك العنف المدرسي & \\
\hline.,., 1 & $(* *) \cdot$, ४ 99 & المستوى الاجتماعي \\
\hline$\cdot, \cdot 1$ & $(* *, r \wedge \mu$ & المستوى الاقتصادي \\
\hline., 0 & $(* *) \cdot, \cdot r q$ & المستوي النقافي \\
\hline$\cdot, \cdot, 1$ & $(* *) \cdot, \varepsilon \wedge 9$ & المستوى المهني \\
\hline$\cdot, ., 1$ & $(* *) \cdot, r \vee \leq$ & الاجتماعى الكلية للقتياس المستوى الثقافى \\
\hline
\end{tabular}

تثشير نتائج الجدول السابق إلى تحقق صدق الفرض الثالث حيث وجد ارتباط موجب دال إحصائياً بين درجات عينة الطلاب على مقياس العنف المدرسي (والمستوى الاجتماعي

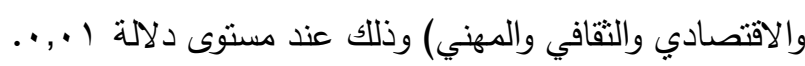


مناقشة نتيجة الفرض الثالث: ينص الفرض على أنه يوجد فروق ذات دالة إحصائية بين سلوك العنف المدرسي والمستوى الاجتماعي والثقافي والمهني والاقتصادي، وللتحقق من لن لهن

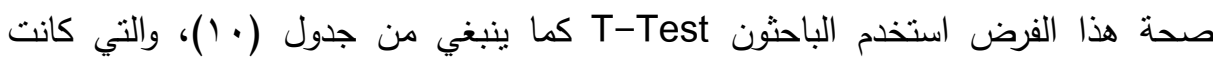

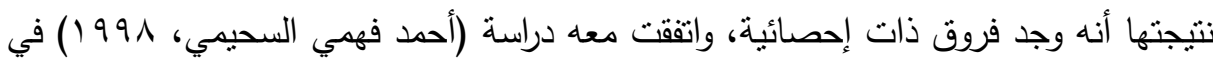
أن من العوامل الني تؤدي على سلوك العنف الأعباء الأسرية والاقتصادية والنفسية

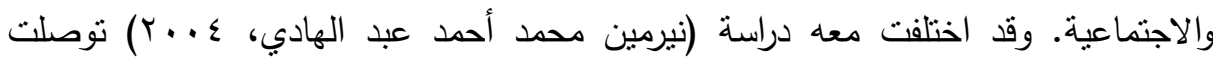

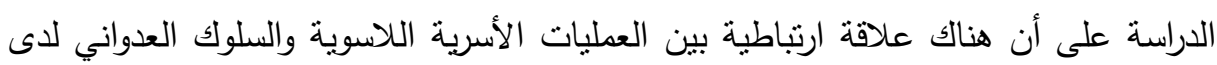

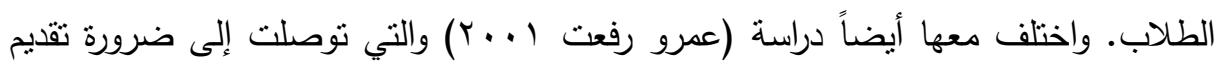
برامج إرشادية بالاشتراط مع أجزة الإعلام لتوعية أولياء الأمور بالطريقة الصحيحة لتربة لتربية الأبناء.

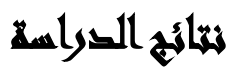

\section{كشفت النتائج عن صحة الفروض التي طرحتها هذه الدراسة في:}

ا. وجود ارتباط دال إحصائياً بين سلوك العنف المدرسي لدى تلميذ المرحلة الإعدادية

$$
\text { والعوامل البيئية (المناخ المدرسي). }
$$

r. وجود ارتباط دال إحصائياً بين سلوك العنف المدرسي لدى تلاميذ المرحلة الإعدادية

$$
\text { والعوامل الفيزيقية (المناخ الأسري). }
$$

r. وجود ارتباط دال إحصائياً بين سلوك العنف الددرسي لدى تلاميذ العيذ المرحلة الإعدادية

$$
\text { والمستوى الاجتماعي والاقتصادي والتقافي والمهني. }
$$

\section{اللجمصياهن}

1-دعوة الأهالي إلى تنقيف أبنائهم إلى ثقافة الحوار سواء في المدرسة أو داخل الأسرة أو من

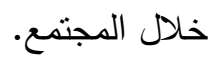

r-تشجيع التلاميذ على التسامح بينهم من خلا تدعيم السلوكيات المتحضرة التي تتهض بالمجتمعات النامية. 
r-الإكثار من الندوات التربوية وبحضور المختصين الاجتماعيين لثرح مساوئ العنف

$$
\text { ومخاطره على الفرد والمجتمع ككل. }
$$

ع-تتمية الوعي لدى الأخصائيين الاجتماعيين بتزويدهم بأساليب علمية جديدة ومنطورة لكيفية

$$
\text { التعامل مع التلاميذ المراهقين. }
$$

ه-ضرورة أن تعمل الدولة على تطوير التعليم والمناهج وبما يخدم العملية التزبوية بحيث

$$
\text { تصبح أكثر فاعلية وكفاءة. }
$$

V- إجراء بحوث ودراسات ممانلة عن العنف لدى التلاميذ في مختلف المناطق والمحافظات

$$
\text { لتكوين صورة أعم وأشمل عن هذه الظاهرة الخطيرة. }
$$

\section{المراليع}

أحمد زايد، وآخرون(ץ + . ץ): العنف في الحياة اليومية في المجتمع المصري، القاهرة، الهيئة العامة لشئون المطابع الأميرية.

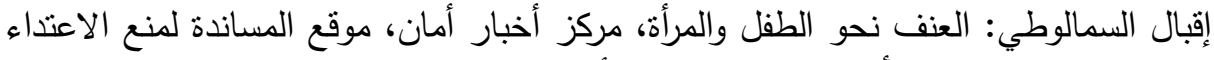

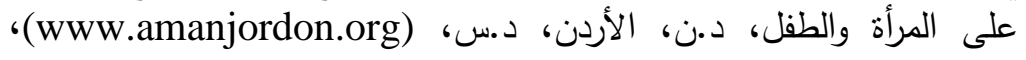
(Www.musanadah.com)

أميمة منير جادو(0 . . ب): العنف المدرسي بين الأسرة والمدرسة، المركز القومي للبحوث

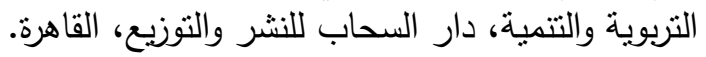

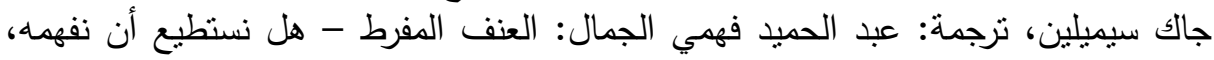

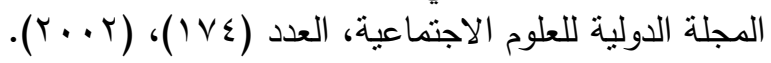

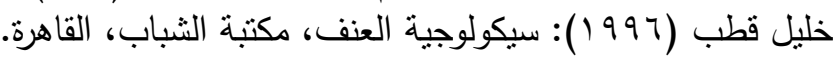

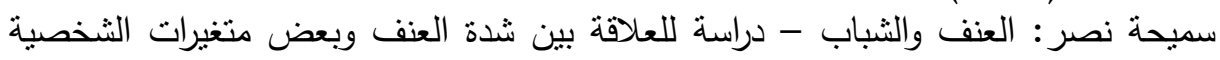

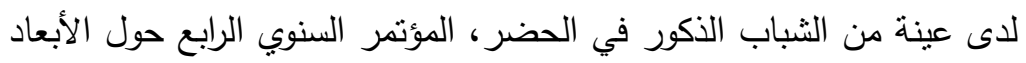

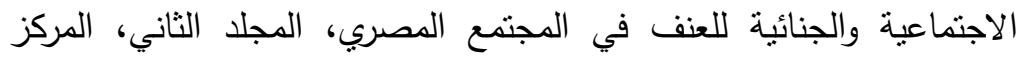

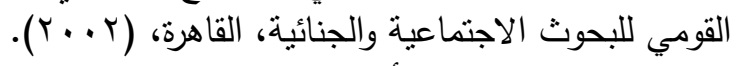

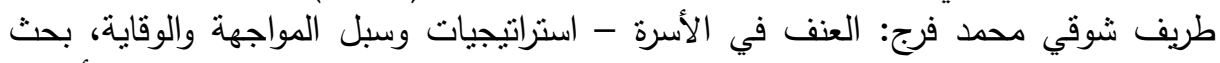
منشور في مجلة كلية الآداب / جامعة بني سويف، العدي العدد الخامس، أكتوبر

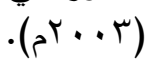


عامر بن شايع بن محمد البشري: دور المرشد الطلابي في الحد من العنف المدرسي من

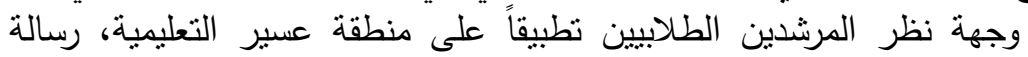

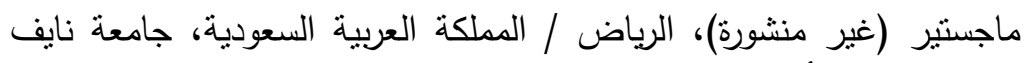

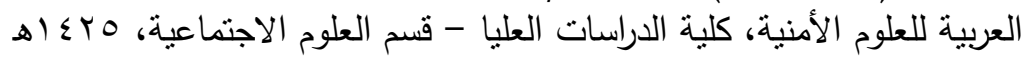

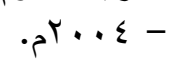

عباس إبراهيم متولي: دراسة لبعض متغيرات الثخصية لدى الأبناء ذوي السلوك العنيف

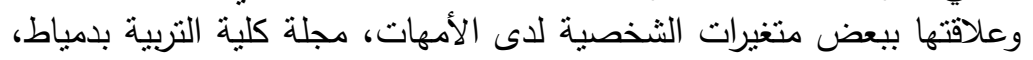

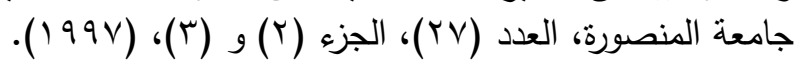

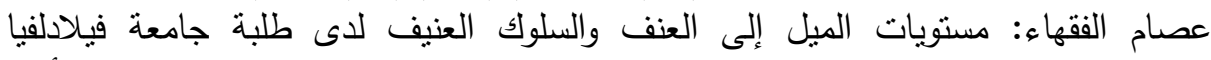

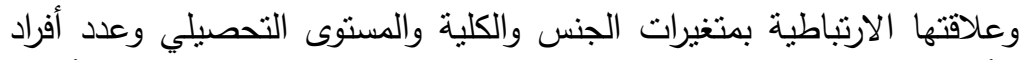

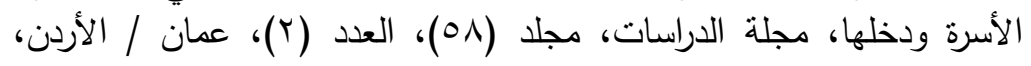

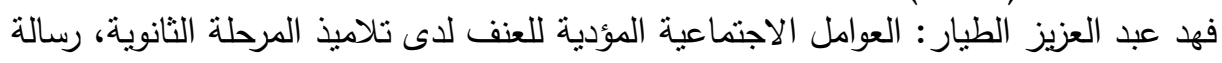

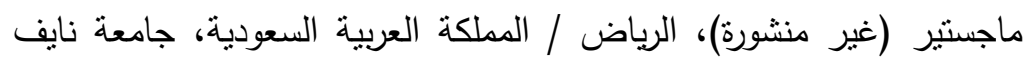

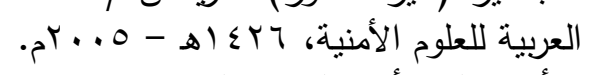

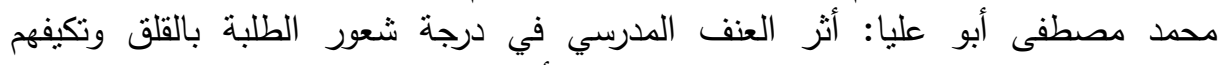

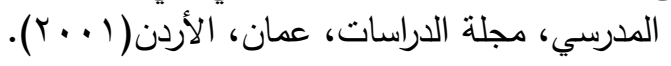

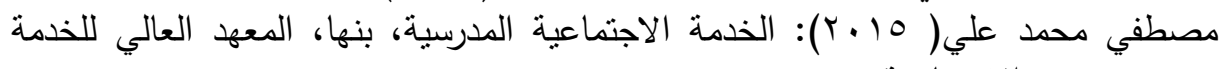
الاجتماعية.

ناصر الثافعي: فن التعامل مع المراهقين مشكلات وحلول، د.ن، داعل د.ب، د.س.

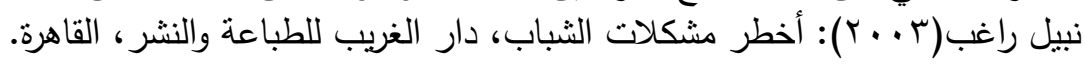


مي عبد المنعم عبد الفتاح وآخرون

\title{
SCHOOL VIOLENCE AMONG ADOLESCENTS AND ITS RELATION TO SOME ENVIRONMENTAL AND PHYSICAL VARIABLES
}

\author{
May A. Abd Elfatah ${ }^{(1)}$; Asmaa M. M. El-Sersy. ${ }^{(2)}$ \\ and Sahr F.M. Mabrouk ${ }^{(3)}$
}

1) Post Grad. Institute of Environmental Studies \& Research, Ain Shams University 2) Institute of Graduate Studies for Children, Ain Shams University 3) Institute of Social Service, Banha University

\begin{abstract}
he objective of the present study is to identify some environmental and physical variables and their relation to the phenomenon of school violence in the preparatory school. We have limited the sample of the study in the study society represented in: Al-Sherbini Preparatory School for Boys in Minya Al-Qamh in Sharkia Governorate, Al-Alfi Preparatory School for Boys in Minya Al- The preparatory study sample consisted of (200) students of middle school age (11-14) years with an average of (13.2) years. The researcher used the scale of school violence (the researcher's preparation), the environmental and physiological climate of adolescents (the researcher's preparation), and the socio-economic socio-economic level scale (preparation of the researcher) : Mohammed Mohamed Bayoumi Khalil 2000). The researcher used the statistical methods of the Alpha Kronbach coefficient to calculate the stability of the study tools, the arithmetic mean, the standard deviation, the correlation coefficient (Pearson) to identify the nature of the relationship between personality characteristics, environmental and physiological climate, Wei's cultural, economic level of the study sample, T.Test test to show the significance of differences between study variables. The results of the study showed a statistically significant positive correlation between the student sample scores on the scale of school violence and the environmental factors at the level of significance of 0.01. There was a statistically 272

$$
\text { المجلد السادس والأربعون، الجزء الثالث، يونيو } 9 \text {. }
$$
\end{abstract}


مجلة العلوم البيئية

معهد الدراسات والبحوث البيئة - جامعة عين شمس لئس

significant correlation between the students' grades on the scale of school violence and physical factors at the level of 0.001, D. Statistically among the sample of the students on the scale of school violence and the social, economic, cultural and vocational level. 